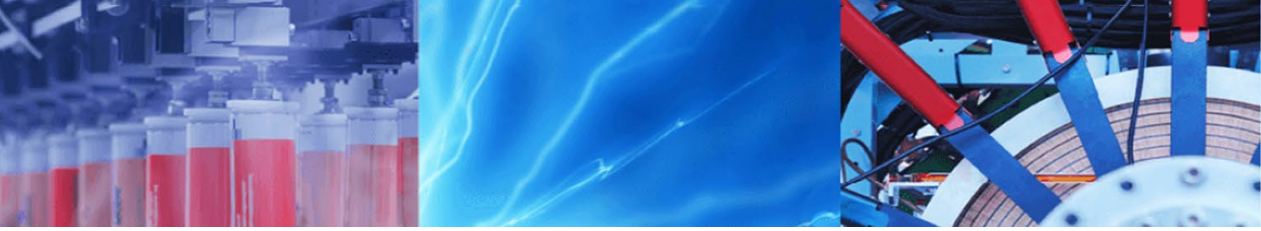

Research Article

\title{
Spectroscopic and computational study of chromone derivatives with antitumor activity: detailed DFT, QTAIM and docking investigations
}

\author{
Y. Sheena Mary ${ }^{1}$ (D) Y. Shyma Mary ${ }^{1} \cdot$ K. S. Resmi ${ }^{2} \cdot$ Ali Shokuhi Rad $^{3}$
}

Received: 2 November 2020 / Accepted: 8 January 2021 / Published online: 16 January 2021

(c) The Author(s) 2021 OPEN

\begin{abstract}
Theoretical investigations of three pharmaceutically active chromone derivatives, (E)-3-((2,3,5,6-tetrafluorophenyl)hydrazono)methyl)-4H-chromen-4-one (TPC), (E)-3-((2-(2,4,6-trifluorophenyl)hydrazono)methyl)-4H-chromen-4-one (FHM) and(E)-3-((2-(perfluorophenyl)hydrazono)methyl)-4H-chromen-4-one (PFH) are reported. Molecular geometries, vibrational spectra, electronic properties and molecular electrostatic potential were investigated using density functional theory. Quantum theory of atoms in molecules (QTAIM) study shows that the maximum of ellipticity parameters in the existing bonds in TPC, FHM and PFH, attributes to the bonds involving in aromatic region points toward the $\pi$-bond interactions in the molecules. Based on energy gap $(1.870,1.649$ and $1.590 \mathrm{eV})$ and electrophilicity index $(20.233,22.581$ and $23.203 \mathrm{eV}$ ) values of TPC, FHM and PFH, we can conclude that all molecules have more biological activity. The molecular electrostatic potential maps were calculated to provide information on the chemical reactivity of the molecule and also to describe the intermolecular interactions. All these studies including docking studies, help a lot in determining the biological activities of chromone derivatives. Activities of chromone derivatives are compared with 5-fluorouracil and azathioprine (antitumor, antiproliferative standards) and were found to be higher than reference ones.
\end{abstract}

Keywords DFT · Chromone · QTAIM · Docking · Antitumor activity

\section{Introduction}

Hydrazine is an industrial raw material that is widely used and toxic biochemical reagent. Hydrazine is widely used for manufacture of drugs, pesticides and chemical dye etc. [1]. Functions such as anti-inflammatory, antibacterial, antitumor, antioxidant, anti-HIV, antiviral and antiallergic are among the various biological properties of hydrazines [2-5]. Hydrazine, colourless inorganic liquid compound, is highly reductive and simple, used as a heating system corrosion inhibitors [6]. Because of the existence of hydrazine structural units in natural and medicininal products, chromones including flavones and related ones create interest in medicinal chemistry [7-9]. The ring system of benzopyrons is fundamental in natural products such as chromones and flavanoids which are common class of compounds which occur naturally and beneficial for human $[10,11]$. The nanocrystalline metal oxide catalyst for styrylchromones preparation was reported by Kunde et al. [12]. Chromone derivatives also act as intermediates to several pharmaceutical, agrochemical and dye stuffs products. Due to chromone derivative's biological

Supplementary information The online version of this article contains supplementary material available at (https://doi.org/10.1007/ s42452-021-04188-1)

Y. Sheena Mary, marysheena2018@rediffmail.com | ${ }^{1}$ Thushara, Neethinagar-64, Kollam, Kerala, India. ${ }^{2}$ Thiruvalluvarpuram Main Street Number 5, Tambaram West, Chennai, Tamilnadu, India ${ }^{3}$ Department of Chemical Engineering, Qaemshahr Branch, Islamic Azad University, Qaemshahr, Iran. 
activities and natural occurrence, these derivatives are important for researchers [13-15]. Arjunan et al. [16] reported the spectroscopic analysis of a formylchromone derivative. Metal complexes from chromone bases have gained significant attention due to their chelating capacity to exhibits successful DNA binding [17]. Mariappan and Sundaraganesan [18] reported the study of a methylchromone derivative. Recently research has been reported on the photophysical behaviour and antimicrobial activity of chromone derivatives [19-21]. Combining pyrone with benzene ring results in two distinct types of benzopyrone rings which are recognized as coumarines and chromones [21]. Kulaczkowska and Bartyzel [22, 23] reported structural analysis of a chromanone derivatives. Chromanones and flavones are an important part of the diet of humans and play a role in the response to biotic and abiotic stress in plants [24, 25]. Kornev et al. [26] reported the reactions of functionalized chromones with triacetic acid lactone. The chromone system's reactivity is determined mainly by the existence and position of a substitute in the pyrone chain [27]. Here we analyzed structural, electronic, biochemical properties of TPC, FHM and PFH chromones theoretically. Antitumor- antibacterial effects of chromone derivatives were compared with 5-fluorouracil (FU) and azathioprine (AP).

\subsection{Computational procedure}

Gaussview program is used to draw the molecular structures (Fig. 1) of TPC, FHM and PFH [28]. Optimizations were made in Gaussian09 at B3LYP/6-311++G(d,p) and no imaginary frequency was obtained [29]. NMR, UV and chemical descriptors were also calculated [30-33]. Chromone derivatives, 5 -fluorouracil and azathioprine
Fig.1 Optimized geometries of a TPC, b FHM, c PFH (a)

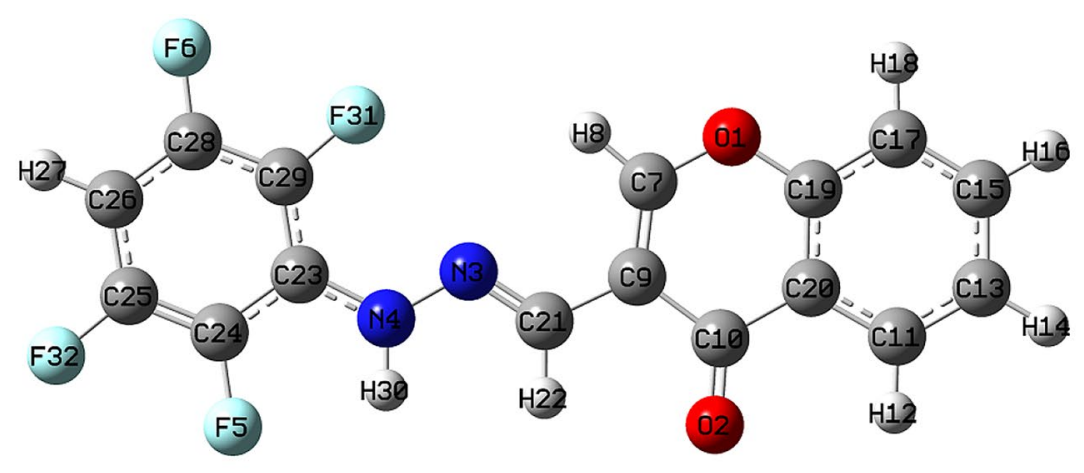

(b)

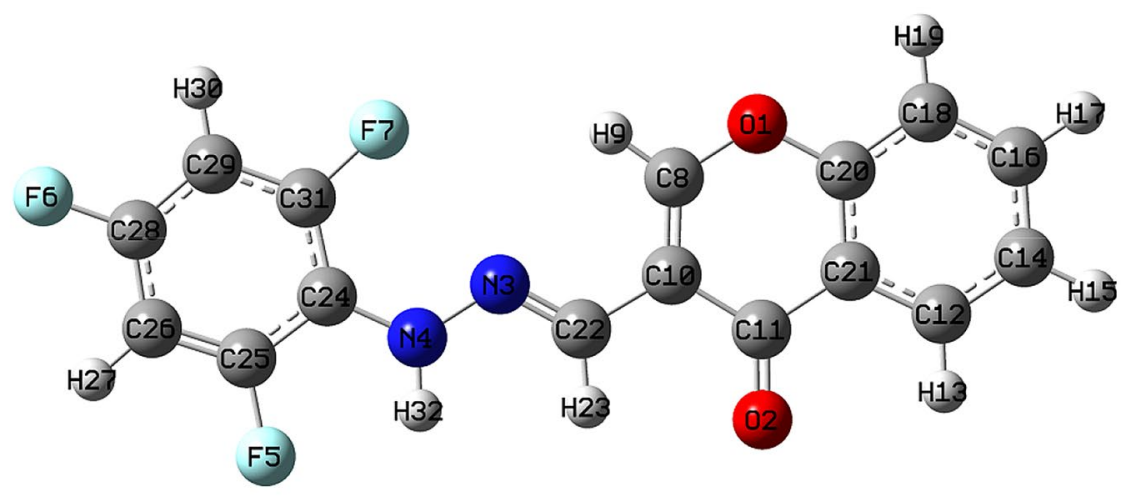

(c)

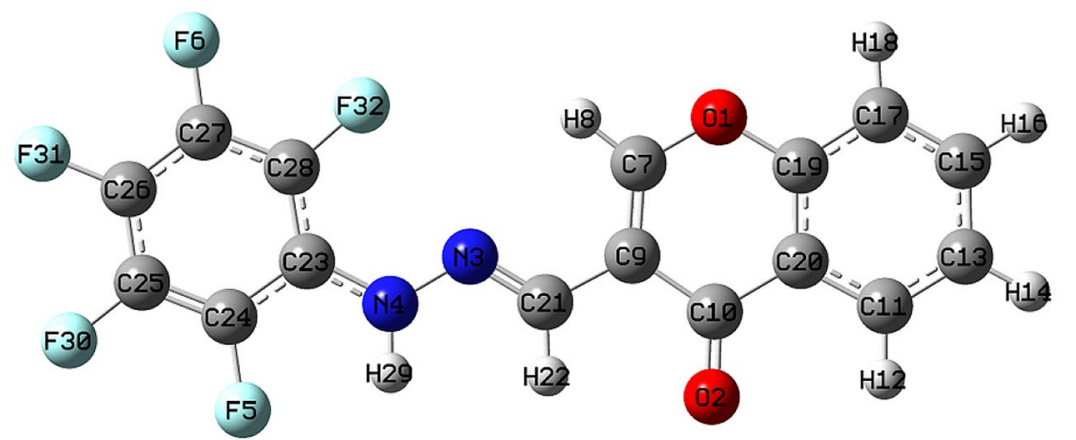


(antitumor-antibacterial referencs) were docked with cancer cell line and references, against PDB ID: 4AT9, 6DM8, 2AYN and 5NAD [34]. Docking were performed by Autodock $[35,36]$ and spectral data were from Slomiak et al. [37]. In the following discussion phenyl and chromone rings are designated as ring 1 and ring2, respectively.

QTAIM as a strong method was utilized to examine the atom-atom interactions in the studied compounds [38, 39]. This method is beneficial to achieve the amounts of electron density and bonding characteristics. AIM analysis was used to find inter-molecular interactions. The electron density $(\rho)$, Laplacian of electron densities $\left(\nabla^{2} \boldsymbol{\rho}\right)$ and ellipticity parameters $(\varepsilon)$ at the bond critical points for TPC, FHM and PFH were obtained from AIM calculations through AIM2000 program (Fig. 2 and table S1), for the evaluation of nature of the interaction. According to QTAIM method, each two interacting atoms were linked by the bond path, and saddle point in BP had a maximum value of electron density (bond critical point-BCP). All assets of each bond were obtained at $\mathrm{BCP}$.

\section{Results and discussion}

\subsection{Molecular structures}

The C-O bond lengths (DFT) are: $1.3473 \AA$, $1.3736 \AA$ (TPC), $1.3730 \AA$, $1.3983 \AA$ (FHM) and $1.3708 \AA, 1.3998 \AA$ (PFH) and experimental values are in the ranges $1.3477-1.3483 \AA$ and 1.3766-1.3738 $\AA$ [37]. The carbonyl bond lengths (DFT) are $1.2313 \AA$, $1.2585 \AA$, $1.2582 \AA$ for TPC, FHM and PFH while the experimental values are from $1.2364 \AA$ to $1.2360 \AA$ [37]. The CN bond lengths are 1.3797 $\AA$, $1.2871 \AA$ for TPC, $1.3869 \AA$, $1.2974 \AA$ for $F H M$ and $1.3810 \AA$, $1.2966 \AA ̊$ for $\mathrm{PFH}$ with experimental values in the ranges, $1.3788-1.3905 \AA$ and 1.2831-1.2816 $\AA$ [37]. The NN bond length is $1.3356 \AA$,
Fig.2 The molecular graphs of a TPC, b FHM, c PFH. Nuclei and bond critical points are represented by big and small spheres small, respectively (green and red circles are bondand ring critical points, respectively). The lines are bond paths (a)

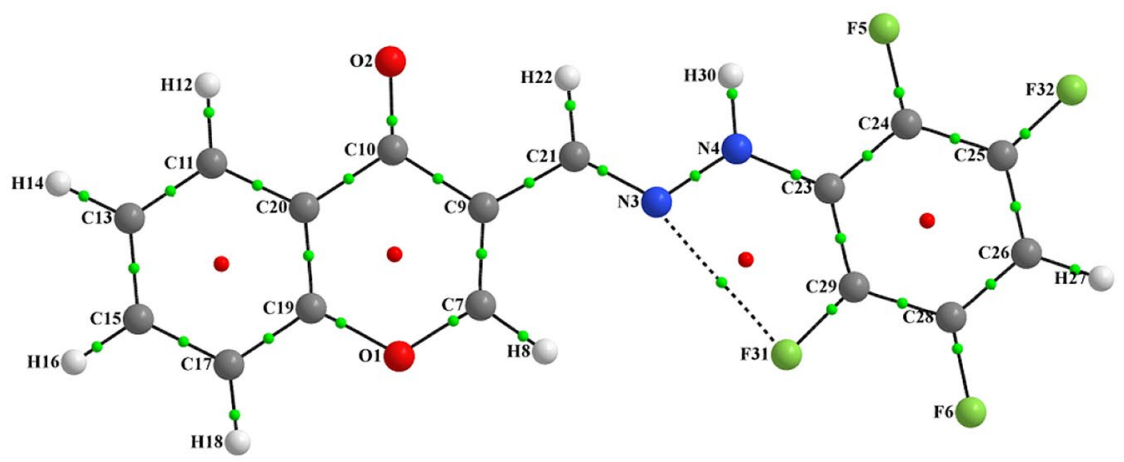

(b)

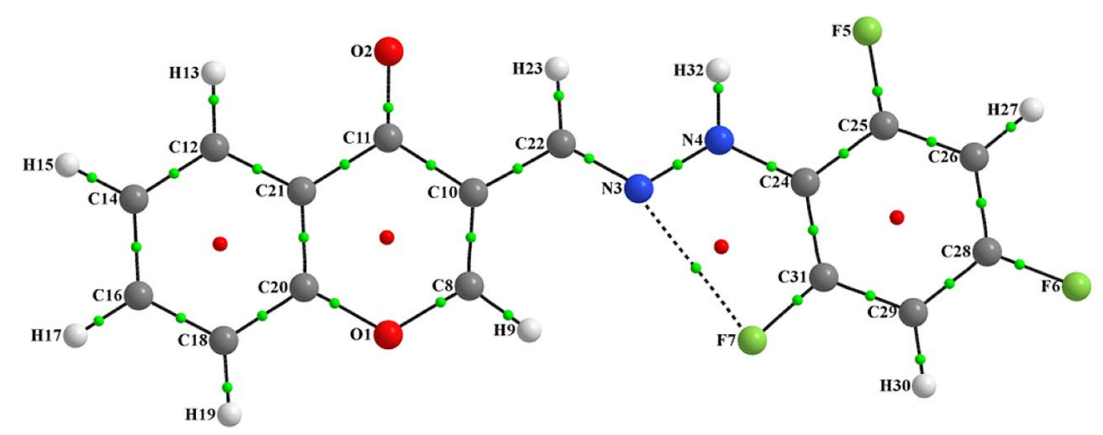

(c) 
$1.3632 \AA, 1.3686 \AA$ for TPC, FHM and PFH and reported experimental values are from $1.3677 \AA$ to $1.3503 \AA$ [37]. The CF bond lengths lie in the ranges 1.3428-1.3425 $\AA$ for TPC, 1.3984-1.3857 ̊̊ for FHM and 1.3899-1.3745 ̊̊ for PFH which are in agreement with experimental results in the range 1.377-1.3618 $\AA$ [37]. The $C=C$ lengths are $1.3593 \AA, 1.3621 \AA$, $1.3622 \AA$ for TPC, FHM and PFH with experimental values in the range 1.3498-1.3550 $\AA$ [37]. The COC bond angles are $119.1^{\circ}$ (TPC), $119.3^{\circ}$ (FHM), $119.4^{\circ}(\mathrm{PFH})$ and $118.3^{\circ}$ (experimental) and CNN angles are $123.3^{\circ}, 117.2^{\circ}$ (TPC), $122.6^{\circ}, 117.1^{\circ}$ (FHM), $120.3^{\circ}, 118.2^{\circ}$ (PFH) with experimental values as $122.8^{\circ}, 116.7^{\circ}[37]$. The experimental values of the angle, $\mathrm{CC}=\mathrm{O}$ are $125.2^{\circ}$ and $122.4^{\circ}$ and for the title compounds, the corresponding angles are, $122.9^{\circ}, 122.9^{\circ}$ (TPC), $122.2^{\circ}, 122.4^{\circ}$ (FHM) and $122.2^{\circ}, 122.5^{\circ}$ (PFH) [37]. Also the CCN angles are in agreement with the reported values: $119.5^{\circ}$ (experimental), $121.3^{\circ}$ (TPC), $120.5^{\circ}$ (FHM) and $120.7^{\circ}$ (PFH) [37]. Most of the dihedral angles are nearly agrees with the experimental results [37].

\subsection{IR and NMR spectra}

The experimental IR spectral data of the title compounds are from Slomiak et al. [37].

The vibrations (table S2) at $3388 \mathrm{~cm}^{-1}$ (IR), $3372 \mathrm{~cm}^{-1}$ (DFT) for TPC, $3387 \mathrm{~cm}^{-1}$ (IR), $3383 \mathrm{~cm}^{-1}$ (DFT) for FHM and $3388 \mathrm{~cm}^{-1}$ (IR), $3382 \mathrm{~cm}^{-1}$ (DFT) for PFH are UNH [40]. Also these IR band has doublet at $3243,3247,3250 \mathrm{~cm}^{-1}$ respectively for TPC, FHM and $\mathrm{PFH}$ with red shift from the computed value showing weakening of $\mathrm{NH}$ bond [41, 42]. The NH deformation is assigned at $1537 / 1541 \mathrm{~cm}^{-1}$ (IR/DFT) for TPC, 1536/1543 $\mathrm{cm}^{-1}$ (IR/DFT) for FHM and $1547 / 1548 \mathrm{~cm}^{-1}$ (IR/DFT) for PFH. The NH stretching modes are reported at $3393 \mathrm{~cm}^{-1}$ (DFT) and at $3380 \mathrm{~cm}^{-1}$ (IR) [43]. The vibrations at 1656, 1619, $1586 \mathrm{~cm}^{-1}$ (IR), 1671, $1617,1590 \mathrm{~cm}^{-1}$ (DFT) for TPC, 1644, 1590, $1564 \mathrm{~cm}^{-1}$ (IR), $1629,1589,1562 \mathrm{~cm}^{-1}$ (DFT) for FHM and 1649, 1596, $1562 \mathrm{~cm}^{-1}$ (IR), 1635, 1594, $1563 \mathrm{~cm}^{-1}$ (DFT) for PFH are the $\mathrm{C}=\mathrm{O}, \mathrm{C}=\mathrm{N}$ and $\mathrm{C}=\mathrm{C}$ stretches [40]. The $\mathrm{C}=\mathrm{O}$ stretching modes are reported at $1682 \mathrm{~cm}^{-1}$ (DFT), $1688 \mathrm{~cm}^{-1}$ (IR) and at $1681 \mathrm{~cm}^{-1}$ (Raman) [54]. UC-O is assigned at $1163,961 \mathrm{~cm}^{-1}$ (IR), 1161, $962 \mathrm{~cm}^{-1}$ (DFT) for TPC, 1147, $958 \mathrm{~cm}^{-1}$ (IR), 1144, $963 \mathrm{~cm}^{-1}$ (DFT) for FHM and 1137, $930 \mathrm{~cm}^{-1}$ (IR) $1143,921 \mathrm{~cm}^{-1}$ (DFT) for PFH [40]. The CO stretching modes are reported at $1082 \mathrm{~cm}^{-1}$ and $997 \mathrm{~cm}^{-1}$ theoretically [45]. NBO interactions produces the downshift of the modes. CF stretches are assigned at 1266, $1201,1108,1070 \mathrm{~cm}^{-1}$ for TPC, $1252,1205,1115 \mathrm{~cm}^{-1}$ for FHM and at 1200, 1097, $989 \mathrm{~cm}^{-1}$ for PFH experimentally [40]. The CF stretching modes are reported at 1112,1076 , $1060 \mathrm{~cm}^{-1}$ [46] and at $1239,1223 \mathrm{~cm}^{-1}$ theoretically [47, 48]. The bands at $1095,1315 \mathrm{~cm}^{-1}$ for TPC, $1082,1313 \mathrm{~cm}^{-1}$ for FHM and $1075,1317 \mathrm{~cm}^{-1}$ for PFH in the IR spectrum are the $\mathrm{N}-\mathrm{N}$ and $\mathrm{C}-\mathrm{N}$ stretching modes of the derivatives [40]. The corresponding DFT values are $1083,1322 \mathrm{~cm}^{-1}$ (TPC), 1083, $1304 \mathrm{~cm}^{-1}$ (FHM) and 1075, $1303 \mathrm{~cm}^{-1}$ (PFH). The $\mathrm{N}-\mathrm{N}$ stretching mode is reported at $1138 \mathrm{~cm}^{-1}$ theoretically [49].

$1 \mathrm{H}$ and $13 \mathrm{C}$ NMR spectra of TPC, FHM and PFH were calculated and it is seen that the chemical shifts are quite similar for TPC, FHM and PFH molecules (table S3). There are four groups of hydrogen in the studied molecules, aromatic, chromone ring, $\mathrm{H}$ atom of $\mathrm{NH}$ and hydrazine group. $\mathrm{H} 8, \mathrm{H} 12$ (TPC and PFH) and H9, H13 (FHM) near to $\mathrm{O}$ atoms whith high electronegativity and its core is less shielded and have high chemical shifts [50]. H22 (TPC and PFH) and $\mathrm{H} 23$ (FHM) are less shielded as it is near to $\mathrm{C}$ and $\mathrm{N}$ (high electronegativity) atoms. For all carbon atoms, near to electronegative atoms, high C NMR chemical shifts. Among the 13C NMR shifts, C10, C19 (TPC and PFH) and $\mathrm{C} 11, \mathrm{C} 20$ (FHM) have the high chemical shift value due to presences of neighbors of high electronegativity [51,52].

\subsection{AIM analysis}

It is established that size of electron density function appraised at BCP can reveal power of a specific bond. This relation has been seen for strong bonds, covalent in nature, and for weak interactions, such as hydrogen bonds. Commonly, higher electron density $(\rho)$ at BCP results in the stronger the bond $[53,54]$. Each of interacting atoms shares electrons in the case of the covalent bond, therefore generating a shared electron pair that is significantly confined in the region between these two atoms. This is additionally accompanied by negative values of Laplacian of electron densities $\left(\nabla^{2} \boldsymbol{\rho}\right)$ given that at BCP of covalent bond, concentration of electron density can be seen. Positive electron density values gives interaction between the corresponding atoms of each compound. The minimum and maximum Electron density are +0.013576 au (for N3-F31) and + 0.394356 au (for O2-C10) in TPC, + 0.013569 au (for N3-F7) and + 0.357139 au (for O2-C11) in FHM, and +0.013743 au (for N3-F32) and +0.357454 au (for $\mathrm{O} 2-\mathrm{C} 10)$ in $\mathrm{PFH}$, respectively. It can be concluded that the $\rho$ value for all bonds except N3-F31 (in TPC), N3-F7 (in FHM), and N3-F32 (in PFH) are in the range of covalent. For the stated bonds, no strongly connection is expected because of their low electron densities. There is good agreement between charge density and Laplacian of charge density $\left(\nabla^{2} \rho\right)$. The $\nabla^{2} \rho(r)$ indicates bond interaction energy which designated on the interaction nature. $A$ positive value of $\nabla^{2} \rho(r)$ can be an indication of non-interaction, whereas a negative value is proof of the covalent interaction. Normally, the negative value of $\nabla^{2} \rho$ associates with covalent interaction and hence the positive values 
for the stated bonds confirms non-covalent interaction. From tables, the maximum of $\varepsilon$ in the existing bonds in TPC, FHM and PFH, attributes to the bonds involving in aromatic region for example C23-C24 and C23-C29 in TPC, C24-C25 and C24-C31 in FHM, and C24-C25, and C7-C9 in $\mathrm{PFH}$, respectively that points toward the $\pi$-bond interactions between the corresponding atoms [55].

\subsection{NBO, electronic and chemical properties}

Due to NBO activity $[56,57]$ the interactions (energies in $\mathrm{kcal} / \mathrm{mol}$ ) are (Table 1): from chromone ring oxygen atom to $\mathrm{O} 1 \rightarrow \mathrm{BD}^{*}(\mathrm{C} 7-\mathrm{C} 9, \mathrm{C} 19-\mathrm{C} 20)(33.63,27.31)$ for $\mathrm{TPC} ; \mathrm{O} 1 \rightarrow \mathrm{BD}^{*}(\mathrm{C} 8-\mathrm{C} 10, \mathrm{C} 20-\mathrm{C} 21)(31.39,25.58)$ for $\mathrm{FHM}$ and $\mathrm{O} 1 \rightarrow \mathrm{BD}^{*}(\mathrm{C} 7-\mathrm{C} 9, \mathrm{C} 19-\mathrm{C} 20)(32.02,25.30)$ for $\mathrm{PFH}$. Also due to the other oxygen atom, $\mathrm{BD}^{*}(\mathrm{C} 9-\mathrm{C} 10$, C10-C20) $(19.70,19.97)$ for TPC; BD* $(C 10-C 11, C 11-C 21)$ $(17.13,17.42)$ for FHM and BD*(C9-C10, C10-C20) (17.20, 17.42) for PFH due to to carbonyl oxygen atom. Nitrogen atom $\mathrm{N} 4$ in all cases produce high interaction given as: $\mathrm{N} 4 \rightarrow \mathrm{BD}^{*}(\mathrm{~N} 3-\mathrm{C} 21, \mathrm{C} 23-\mathrm{C} 29)(30.91,43.23)$ for TPC, N4 $\rightarrow B^{*}(N 3-C 22, C 24-C 31)(31.86,42.09)$ for FHM and N4 $\rightarrow \mathrm{BD}^{*}(\mathrm{~N} 3-\mathrm{C} 21, \mathrm{C} 23-\mathrm{C} 28)(29.52,45.69)$ for $\mathrm{PFH}$. Due to fluorine atoms, the interactions are: $\mathrm{F} 5 \rightarrow \mathrm{BD}^{*}(\mathrm{C} 24-\mathrm{C} 25)$ (17.36), $\mathrm{F} 6 \rightarrow \mathrm{BD}^{*}(\mathrm{C} 26-\mathrm{C} 28)$ (20.56), $\mathrm{F} 31 \rightarrow \mathrm{BD}^{*}(\mathrm{C} 23-\mathrm{C} 29)$ (18.70), $\mathrm{F} 32 \rightarrow \mathrm{BD}^{*}(\mathrm{C} 24-\mathrm{C} 25)$ (20.96) for TPC; F5 $\rightarrow \mathrm{BD}^{*}(\mathrm{C} 25-\mathrm{C} 26)$ (16.17), F6 $\rightarrow \mathrm{BD}^{*}(\mathrm{C} 28-\mathrm{C} 29)$ $(17.78), F 7 \rightarrow \mathrm{BD}^{*}(\mathrm{C} 24-\mathrm{C} 31)$ (17.77) forFHMandF5 $\rightarrow \mathrm{BD}^{*}(\mathrm{C} 24-\mathrm{C} 25)$ (16.46), $\mathrm{F} 6 \rightarrow \mathrm{BD}^{*}(\mathrm{C} 26-\mathrm{C} 27)$ (18.87), $\mathrm{F} 30 \rightarrow \mathrm{BD}^{*}(\mathrm{C} 24-\mathrm{C} 25)$ (19.22), F31 $\rightarrow \mathrm{BD}^{*}(\mathrm{C} 26-\mathrm{C} 27)$ (18.06), $\mathrm{F} 32 \rightarrow \mathrm{BD}^{*}(\mathrm{C} 27-\mathrm{C} 28)$ (17.42) for PFH.

FMOs often play dominant roles in molecular systems. The fundamental idea of this theory can be abridged in the form of a simple rule telling the condition for a simple course of the reaction by the requirement of the maximal positive overlap between LUMO (empty state) and HOMO (filled state) orbitals. LUMO and HOMO are related to electron affinity and ionization potential $[58,59]$. These orbitals help to understand the chemical stability and the reactivity (Fig. 3). HOMO is over the ring1 and oxygen containing portion of ring2 for all molecules and over fluorine atoms of FHM and PFH while for TPC, it is over the fluorine atoms near to the $\mathrm{CN}$ attached bond. For all compounds, LUMO is over the ring2. HOMO and LUMO levels are $-7.086 \mathrm{eV},-5.216 \mathrm{eV}$ for TPC, $-6.928 \mathrm{eV},-5.279 \mathrm{eV}$ for FHM, $-6.869 \mathrm{eV},-5.279 \mathrm{eV}$ for PFH and energy gap varies in the order, TPC $>$ FHM $>$ PFH (Table 2). A molecule with a small energygap is more polarizable and is generally associated with high chemical reactivity and low kinetic stability and is also termed as the soft molecule. It ensures an incrase in chemical stability of the molecule because the smaller value of energy gap indicates easiness of the electron excitation from HOMO to LUMO and it reflects
Table 1 Interaction energies from NBO analysis for (a) TPC (b) FHM (c) $\mathrm{PFH}$

\begin{tabular}{|c|c|c|}
\hline Donor NBO & Acceptor NBO & $\begin{array}{l}\text { Interaction } \\
\text { energy } \mathrm{E}(2) \mathrm{kcal} / \\
\mathrm{mol}\end{array}$ \\
\hline
\end{tabular}

(a)TPC

$\mathrm{BD}(\mathrm{C7}-\mathrm{C} 9)$

$\mathrm{BD}(\mathrm{C7}-\mathrm{C} 9)$

$\mathrm{BD}(\mathrm{C} 11-\mathrm{C} 13)$

$\mathrm{BD}(\mathrm{C} 11-\mathrm{C} 13)$

$\mathrm{BD}(\mathrm{C} 15-\mathrm{C} 17)$

$\mathrm{BD}(\mathrm{C} 15-\mathrm{C} 17)$

$\mathrm{BD}(\mathrm{C} 19-\mathrm{C} 20)$

$\mathrm{BD}(\mathrm{C} 19-\mathrm{C} 20)$

$\mathrm{BD}(\mathrm{C} 19-\mathrm{C} 20)$

$\mathrm{BD}(\mathrm{C} 23-\mathrm{C} 29)$

$\mathrm{BD}(\mathrm{C} 23-\mathrm{C} 29)$

$\mathrm{BD}(\mathrm{C} 24-\mathrm{C} 25)$

$\mathrm{BD}(\mathrm{C} 24-\mathrm{C} 25)$

$\mathrm{BD}(\mathrm{C} 26-\mathrm{C} 28)$

$\mathrm{BD}(\mathrm{C26}-\mathrm{C28})$

LPO1

LPO1

LPO2

LPO2

LPN4

LPN4

LPF5

LPF6

LPF31

LPF32

(b) FHM

$\mathrm{BD}(\mathrm{C} 8-\mathrm{C} 10)$

$\mathrm{BD}(\mathrm{C} 8-\mathrm{C} 10)$

$\mathrm{BD}(\mathrm{C} 12-\mathrm{C} 14)$

$\mathrm{BD}(\mathrm{C} 12-\mathrm{C} 14)$

$\mathrm{BD}(\mathrm{C} 16-\mathrm{C} 18)$

$\mathrm{BD}(\mathrm{C} 16-\mathrm{C} 18)$

$\mathrm{BD}(\mathrm{C} 20-\mathrm{C} 21)$

$\mathrm{BD}(\mathrm{C} 20-\mathrm{C} 21)$

$\mathrm{BD}(\mathrm{C} 20-\mathrm{C} 21)$

$\mathrm{BD}(\mathrm{C} 24-\mathrm{C} 31)$

$\mathrm{BD}(\mathrm{C} 24-\mathrm{C} 31)$

$\mathrm{BD}(\mathrm{C} 25-\mathrm{C} 26)$

$\mathrm{BD}(\mathrm{C} 25-\mathrm{C} 26)$

$\mathrm{BD}(\mathrm{C} 28-\mathrm{C} 29)$

$\mathrm{BD}(\mathrm{C} 28-\mathrm{C} 29)$

LPO1

LPO1

LPO2

$\mathrm{LPO} 2$

$\begin{array}{cc}\mathrm{BD} *(\mathrm{O} 2-\mathrm{C} 10) & 22.46 \\ \mathrm{BD}^{*}(\mathrm{~N} 3-\mathrm{C} 21) & 16.15 \\ \mathrm{BD}^{*}(\mathrm{C} 15-\mathrm{C} 17) & 21.56 \\ \mathrm{BD}^{*}(\mathrm{C} 19-\mathrm{C} 20) & 18.14 \\ \mathrm{BD}^{*}(\mathrm{C} 11-\mathrm{C} 13) & 16.29 \\ \mathrm{BD}^{*}(\mathrm{C} 19-\mathrm{C} 20) & 21.88 \\ \mathrm{BD}^{*}(\mathrm{CO} 2-\mathrm{C} 10) & 21.24 \\ \mathrm{BD}^{*}(\mathrm{C} 11-\mathrm{C} 13) & 18.37 \\ \mathrm{BD}^{*}(\mathrm{C} 15-\mathrm{C} 17) & 16.43 \\ \mathrm{BD}^{*}(\mathrm{C} 24-\mathrm{C} 25) & 16.85 \\ \mathrm{BD}^{*}(\mathrm{C} 26-\mathrm{C} 28) & 23.58 \\ \mathrm{BD}^{*}(\mathrm{C} 23-\mathrm{C} 29) & 19.84 \\ \mathrm{BD}^{*}(\mathrm{C} 26-\mathrm{C} 28) & 15.30 \\ \mathrm{BD}^{*}(\mathrm{C} 23-\mathrm{C} 29) & 16.86 \\ \mathrm{BD}^{*}(\mathrm{C} 24-\mathrm{C} 25) & 22.56 \\ \mathrm{BD}^{*}(\mathrm{C} 7-\mathrm{C} 9) & 33.63 \\ \mathrm{BD}^{*}(\mathrm{C} 19-\mathrm{C} 20) & 27.31 \\ \mathrm{BD}^{*}(\mathrm{C} 9-\mathrm{C} 10) & 19.70 \\ \mathrm{BD}^{*}(\mathrm{C} 10-\mathrm{C} 20) & 19.97 \\ \mathrm{BD}^{*}(\mathrm{~N} 37-\mathrm{C} 21) & 30.91 \\ \mathrm{BD}^{*}(\mathrm{C} 23-\mathrm{C} 29) & 43.23 \\ \mathrm{BD}^{*}(\mathrm{C} 24-\mathrm{C} 25) & 17.36 \\ \mathrm{BD}^{*}(\mathrm{C} 26-\mathrm{C} 28) & 20.56 \\ \mathrm{BD}^{*}(\mathrm{C} 23-\mathrm{C} 29) & 18.70 \\ \mathrm{BD}^{*}(\mathrm{C} 24-\mathrm{C} 25) & 20.96\end{array}$

$\begin{array}{rr}\mathrm{BD} *(\mathrm{O} 2-\mathrm{C} 11) & 23.80 \\ \mathrm{BD}^{*}(\mathrm{~N} 3-\mathrm{C} 22) & 16.59 \\ \mathrm{BD}^{*}(\mathrm{C} 16-\mathrm{C} 18) & 21.55 \\ \mathrm{BD}^{*}(\mathrm{C} 20-\mathrm{C} 21) & 18.89 \\ \mathrm{BD}^{*}(\mathrm{C} 12-\mathrm{C} 14) & 16.62 \\ \mathrm{BD}^{*}(\mathrm{C} 20-\mathrm{C} 21) & 22.34 \\ \mathrm{BD} *(\mathrm{O} 2-\mathrm{C} 11) & 23.02 \\ \mathrm{BD}^{*}(\mathrm{C} 12-\mathrm{C} 14) & 18.06 \\ \mathrm{BD}^{*}(\mathrm{C} 16-\mathrm{C} 21) & 16.81 \\ \mathrm{BD}(\mathrm{C} 25-\mathrm{C} 26) & 20.54 \\ \mathrm{BD}^{*}(\mathrm{C} 28-\mathrm{C} 29) & 19.84 \\ \mathrm{BD}^{*}(\mathrm{C} 24-\mathrm{C} 31) & 17.71 \\ \mathrm{BD}^{*}(\mathrm{C} 28-\mathrm{C} 29) & 19.06 \\ \mathrm{BD}^{*}(\mathrm{C} 24-\mathrm{C} 31) & 20.49 \\ \mathrm{BD}^{*}(\mathrm{C} 25-\mathrm{C} 26) & 19.55 \\ \mathrm{BD}^{*}(\mathrm{C} 8-\mathrm{C} 10) & 31.39 \\ \mathrm{BD}^{*}(\mathrm{C} 20-\mathrm{C} 21) & 25.58 \\ \mathrm{BD}^{*}(\mathrm{C} 10-\mathrm{C} 11) & 17.13 \\ \mathrm{BD}^{*}(\mathrm{C} 11-\mathrm{C} 21) & 17.42 \\ \mathrm{BD}^{*}(\mathrm{~N} 3-\mathrm{C} 22) & 31.86\end{array}$


Table 1 (continued)

\begin{tabular}{|c|c|c|}
\hline Donor NBO & Acceptor NBO & $\begin{array}{l}\text { Interaction } \\
\text { energy } \mathrm{E}(2) \mathrm{kcal} / \\
\mathrm{mol}\end{array}$ \\
\hline LPN4 & $B D^{*}(C 24-C 31)$ & 42.09 \\
\hline LPF5 & $B D^{*}(C 25-C 26)$ & 16.17 \\
\hline LPF6 & $B D^{*}(C 28-C 29)$ & 17.78 \\
\hline \multicolumn{3}{|l|}{ (c) $P F H$} \\
\hline $\mathrm{BD}(\mathrm{C} 7-\mathrm{C} 9)$ & $\mathrm{BD}^{*}(\mathrm{O} 25-\mathrm{C} 10)$ & 23.79 \\
\hline $\mathrm{BD}(\mathrm{C} 7-\mathrm{C} 9)$ & $B D^{*}(\mathrm{~N} 35-\mathrm{C} 21)$ & 17.39 \\
\hline $\mathrm{BD}(\mathrm{C} 11-\mathrm{C} 13)$ & $B D^{*}(\mathrm{C} 15-\mathrm{C} 17)$ & 21.52 \\
\hline $\mathrm{BD}(\mathrm{C} 11-\mathrm{C} 13)$ & $B D^{*}(C 19-C 20)$ & 19.06 \\
\hline $\mathrm{BD}(\mathrm{C} 15-\mathrm{C} 17)$ & $\mathrm{BD}^{*}(\mathrm{C} 11-\mathrm{C} 13)$ & 16.63 \\
\hline $\mathrm{BD}(\mathrm{C} 15-\mathrm{C} 17)$ & $B D^{*}(C 19-C 20)$ & 22.54 \\
\hline $\mathrm{BD}(\mathrm{C} 19-\mathrm{C} 20)$ & $B D^{*}(\mathrm{O} 25-\mathrm{C} 10)$ & 23.11 \\
\hline $\mathrm{BD}(\mathrm{C} 19-\mathrm{C} 20)$ & $\mathrm{BD}^{*}(\mathrm{C} 11-\mathrm{C} 13)$ & 17.95 \\
\hline $\mathrm{BD}(\mathrm{C} 19-\mathrm{C} 20)$ & $\mathrm{BD}^{*}(\mathrm{C} 15-\mathrm{C} 17)$ & 16.76 \\
\hline $\mathrm{BD}(\mathrm{C} 23-\mathrm{C} 28)$ & $B D^{*}(C 24-C 25)$ & 18.34 \\
\hline $\mathrm{BD}(\mathrm{C} 23-\mathrm{C} 28)$ & $B D^{*}(C 26-C 27)$ & 23.12 \\
\hline $\mathrm{BD}(\mathrm{C} 24-\mathrm{C} 25)$ & $B D^{*}(C 23-C 28)$ & 18.40 \\
\hline $\mathrm{BD}(\mathrm{C} 24-\mathrm{C} 25)$ & $B D^{*}(C 26-C 27)$ & 16.97 \\
\hline $\mathrm{BD}(\mathrm{C} 26-\mathrm{C} 27)$ & $B D^{*}(C 23-C 28)$ & 17.04 \\
\hline $\mathrm{BD}(\mathrm{C} 26-\mathrm{C} 27)$ & $B D^{*}(C 24-C 25)$ & 20.95 \\
\hline LPO1 & $\mathrm{BD}^{*}(\mathrm{C} 7-\mathrm{C} 9)$ & 32.02 \\
\hline LPO1 & $\mathrm{BD}^{*}(\mathrm{C} 19-\mathrm{C} 20)$ & 25.30 \\
\hline LPO2 & $\mathrm{BD}^{*}(\mathrm{C} 9-\mathrm{C} 10)$ & 17.20 \\
\hline LPO2 & $B D^{*}(C 10-C 20)$ & 17.42 \\
\hline LPN4 & $\mathrm{BD}^{*}(\mathrm{~N} 3-\mathrm{C} 21)$ & 29.52 \\
\hline LPN4 & $B D^{*}(C 23-C 28)$ & 45.69 \\
\hline LPF5 & $B D^{*}(C 24-C 25)$ & 16.46 \\
\hline LPF6 & $B D^{*}(C 26-C 27)$ & 18.87 \\
\hline LPF30 & $B D^{*}(C 24-C 25)$ & 19.22 \\
\hline LPF31 & $B D^{*}(C 26-C 27)$ & 18.06 \\
\hline LPF32 & $B D^{*}(C 23-C 28)$ & 17.42 \\
\hline
\end{tabular}

the biological activity of the molecule $[43,60,61]$. The title molecules are electrophilic in nature with a negative electron donating power. This is in agreement with the high electron affinity values. Hence it can be concluded that the title compounds are inherently reactive and this feature is responsible for various biological activities [62-65].
To estimate the antitumor-antiproliferative activities of TPC, FHM and PFH, chemical descriptors were noted for 5-fluorouracil (anticancer) and azathioprine (antiproliferative drug). Dipole moment of 5 -fluorouracil is in between the values of title compounds. From the results, if 5-fluorouracil is an antitumor drug, the title compounds may also have same activity. Similar explanation is applicatble for antiproliferative activity [66].

MEP allows us to search the most reactive nucleophilic and electrophilic sites of a molecule against the reactive biological potentials [67]. Electrophilic portions show attraction, while nucleophilic indicates repulsion. Electrostatic potential diagrams are illustrated in Fig. 4. The red and yellow colours represent the most electronegative electrostatic potential. That is atoms in this region have a tendency to attract electrons (electrophilic). In the MEP plot, blue colour indicates the most electropositive potential and the red colour indicates the most electronegative potential. Regions where the potentials are zero are denoted by green colour. As from MEP surface negative region is on $\mathrm{O}, \mathrm{F}$ atoms and phenyl rings for $\mathrm{FHM}$, TPC and $\mathrm{PFH}$ with nucleophilic portions near $\mathrm{H}$ atoms with $\mathrm{NH}$ group showing the biological activity [44].

The UV-Vis absorption (Fig.S1) are at $310 \mathrm{~nm}, 278 \mathrm{~nm}$ for TPC, $312 \mathrm{~nm}, 284 \mathrm{~nm}$ for FHM and at $311 \mathrm{~nm}, 281 \mathrm{~nm}$ for PFH. DOS spectrum (Fig.S2) characterize the energy levels per unit energy increment and its composing energy. The displaying study per orbital shows that the green and red line in these curves correspond to HOMO and LUMO energy levels.

NLO properties are presented in table S4 [68]. First order hyperpolarizability $\left(\times 10^{-30} \mathrm{esu}\right)$ varies as: $\mathrm{FHM}>\mathrm{TPC}>\mathrm{PFH}$ which are 140, 134 and 69 times that of urea and second order value is also high for all derivatives $[69,70]$.

\subsection{Molecular docking}

PASS analysis [71] gives activities, HMGCS2 expression enhancer, $\mathrm{Mcl}-1$ antagonist, Thiol protease inhibitor and antiproliferative activities. Receptors, 4AT9, 6DM8, 2AYN and 5 NAD were obtained from protein data bank website. ILF3 promotes proliferation and migration in breast
Fig.3 HOMO-LUMO plots of a TPC, b FHM, c PFH

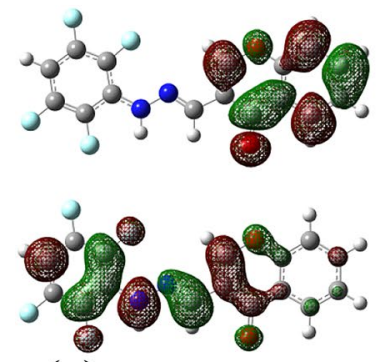

(a)

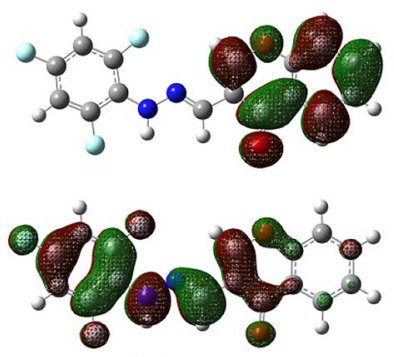

(b)
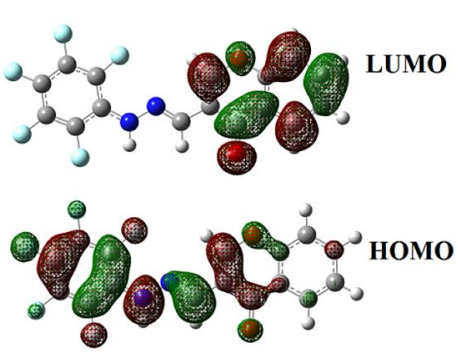

(c) 
Table 2 Chemical descriptors

\begin{tabular}{llllllll}
\hline Molecule & $\mathrm{I}=-\mathrm{E}_{\mathrm{HOMO}}$ & $\mathrm{A}=-\mathrm{E}_{\mathrm{LUMO}}$ & $\Delta \mathrm{E}$ & $\eta=(\mathrm{I}-\mathrm{A}) / 2$ & $\chi=(I+\mathrm{A}) / 2$ & $\omega$ & Dipole moment \\
\hline TPC & 7.086 & 5.216 & 1.870 & 0.935 & 6.151 & 20.233 & 2.7693 \\
FHM & 6.928 & 5.279 & 1.649 & 0.825 & 6.104 & 22.581 & 2.3525 \\
PFH & 6.869 & 5.279 & 1.590 & 0.795 & 6.074 & 23.203 & 4.7226 \\
5-Fluorouracil (FU) & 7.915 & 3.999 & 3.916 & 1.958 & 5.957 & 9.062 & 4.2979 \\
Azathioprine (AP) & 7.268 & 4.493 & 2.775 & 1.388 & 5.881 & 12.459 & 5.2752 \\
\hline
\end{tabular}

Dipole moment is in Debye and all other in eV

Fig.4 MEP plots of a TPC, $\mathbf{b}$ FHM, c PFH (a)

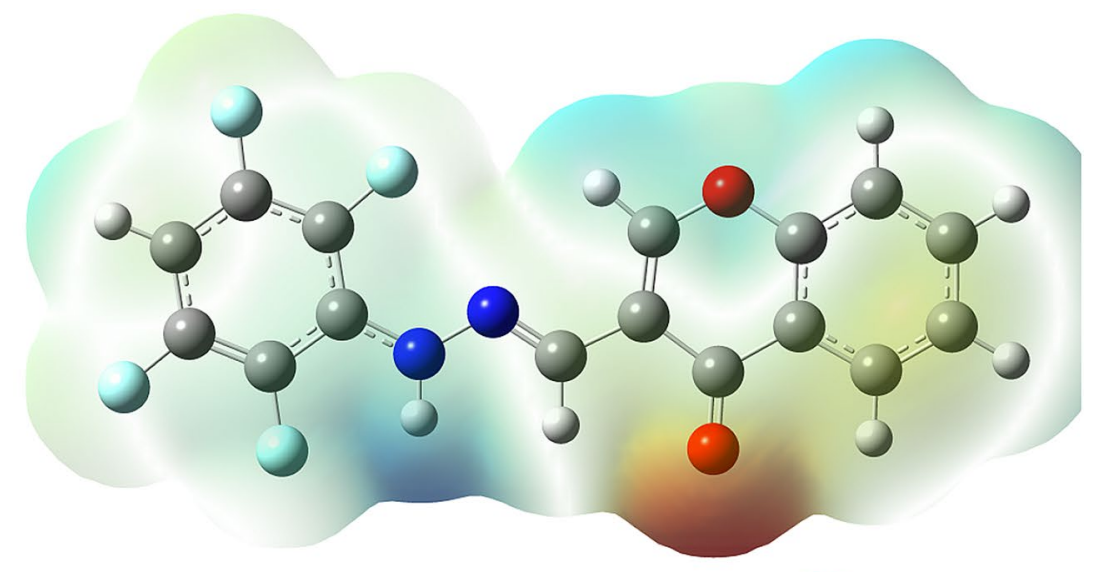

(b)

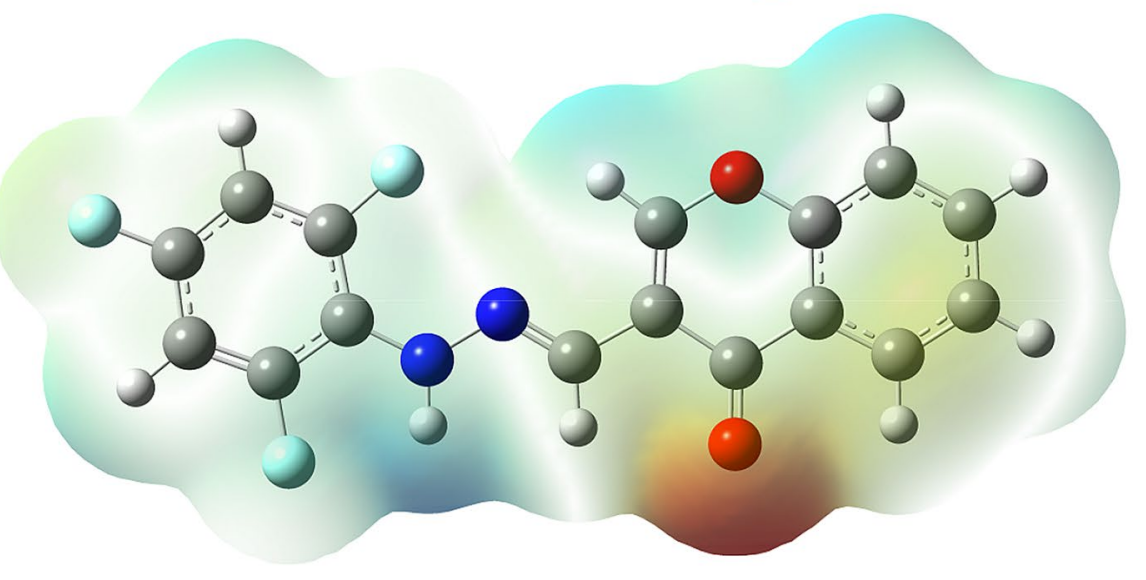

(c)

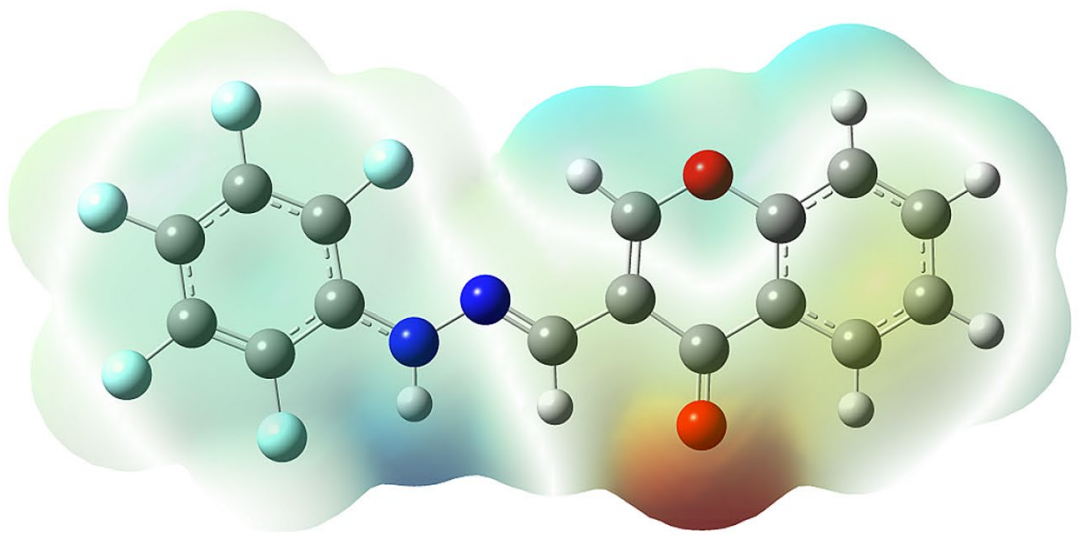


cancer cells, at least partly by promoting $\mathrm{CDH} 11$ expression [72]. Frequent over expression of $\mathrm{MCL}-1$ in primary and drug-resistant human cancer cells makes it an attractive therapeutic target for cancer [73-75]. Anitcancer and antibacterial properties of chromone derivatives were investigated using selected PDB by using Audock software $[35,36]$ and Patchdock server [76-78]. 2D Interactions are shown in Fig.S3. With these the docked ligands form stable complex and has high binding affinity values (Table 3 ). From the results of Autodock, TPC and PFH have maximum binding energy values of $-9.6 \mathrm{kcal} / \mathrm{mol}$ for $6 \mathrm{DM} 8$ while for FHM binding energy is $-8.6 \mathrm{kcal} / \mathrm{mol}$ for $5 \mathrm{NAD}$. For all the PDBs, the binding energies vary from $-7.9 \mathrm{kcal} / \mathrm{mol}$ to $-9.6 \mathrm{kcal} / \mathrm{mol}$. For AP and FU according to Autodock results, the binding energies are in the range $-6.6 \mathrm{kcal} /$ $\mathrm{mol}$ to $-7.4 \mathrm{kcal} / \mathrm{mol}$ and $-5.0 \mathrm{kcal} / \mathrm{mol}$ to $-5.7 \mathrm{kcal} / \mathrm{mol}$. For TPC and FHM, Patchdock server docking give maximum binding energy (table S5) for the PDB:6DM8 with values $-41.41 \mathrm{kcal} / \mathrm{mol}$ and $-43.70 \mathrm{kcal} / \mathrm{mol}$. For $\mathrm{PFH}$ the energy is high for $2 A Y N$ with a value $-38.46 \mathrm{kcal} / \mathrm{mol}$. $\mathrm{AP}$ and $\mathrm{FU}$ also have energies in the ranges $-39.44 \mathrm{kcal} /$ $\mathrm{mol}$ to $-45.62 \mathrm{kcal} / \mathrm{mol}$ (AP) and $-20.80 \mathrm{kcal} / \mathrm{mol}$ to $-23.03 \mathrm{kcal} / \mathrm{mol}$ (FU). Consequently, all derivatives show activity against these inhibitors and can develop new lead medication as in cancer treatment and antiproliferative

Table 3 The binding affinity values of different poses the compounds predicted by Autodock Vina

\begin{tabular}{|c|c|c|c|c|}
\hline \multirow[t]{2}{*}{ Compound } & \multirow[t]{2}{*}{ Protein } & \multirow[t]{2}{*}{$\begin{array}{l}\text { Affinity } \\
\text { (kcal/mol) }\end{array}$} & \multicolumn{2}{|c|}{$\begin{array}{l}\text { Distance from best } \\
\text { mode }(\AA)\end{array}$} \\
\hline & & & RMSD I.b & RMSD u.b \\
\hline TPC & 4AT9 & -8.2 & 0.000 & 0.000 \\
\hline TPC & 6DM8 & -9.6 & 0.000 & 0.000 \\
\hline TPC & 2AYN & -8.6 & 0.000 & 0.000 \\
\hline TPC & $5 N A D$ & -8.8 & 0.000 & 0.000 \\
\hline FHM & 4AT9 & -7.9 & 0.000 & 0.000 \\
\hline FHM & 6DM8 & -8.0 & 0.000 & 0.000 \\
\hline FHM & $2 \mathrm{AYN}$ & -8.4 & 0.000 & 0.000 \\
\hline FHM & $5 N A D$ & -8.6 & 0.000 & 0.000 \\
\hline PFH & 4AT9 & -8.4 & 0.000 & 0.000 \\
\hline PFH & 6DM8 & -9.6 & 0.000 & 0.000 \\
\hline PFH & $2 \mathrm{AYN}$ & -8.7 & 0.000 & 0.000 \\
\hline PFH & $5 N A D$ & -9.1 & 0.000 & 0.000 \\
\hline AP & 4AT9 & -6.8 & 0.000 & 0.000 \\
\hline AP & 6DM8 & -7.4 & 0.000 & 0.000 \\
\hline AP & $2 \mathrm{AYN}$ & -7.1 & 0.000 & 0.000 \\
\hline $\mathrm{AP}$ & $5 N A D$ & -6.6 & 0.000 & 0.000 \\
\hline FU & 4AT9 & -5.0 & 0.000 & 0.000 \\
\hline FU & 6DM8 & -5.3 & 0.000 & 0.000 \\
\hline FU & $2 \mathrm{AYN}$ & -5.6 & 0.000 & 0.000 \\
\hline FU & $5 N A D$ & -5.7 & 0.000 & 0.000 \\
\hline
\end{tabular}

effects. As seen in table $\mathrm{S} 6$ of Autodock results, TPC, FHM and PFH are interacting with the all tarrget proteins.

\subsection{Interactions of TPC, FHM, PFH with 4AT9}

\subsubsection{For TPC}

The active amino acid Gln358, lle359 forms conventional $\mathrm{H}$-bond interaction with same fluorine atom at the distance of 3.39, $3.29 \AA$ whereas Arg94 shows conventional $\mathrm{H}$-bond and carbon hydrogen bond interaction with $\mathrm{C}=\mathrm{N}$ bond at the distance of $3.39,3.63 \AA$. Val98 have two halogen interactions and lle395 has a halogen interaction with fluorine atoms at the distance of 2.84, 3.34 and $3.18 \AA$. Arg94 form hydrophobic $\pi$-sigma interaction and Met93 having a $\pi$-sulfur interaction with ring centres of choromone structure are at the distance of 3.94, 5.69 $\AA$. Val357, Pro361 shows hydrophobic $\pi$-alkyl interaction having the distances of $4.38,5.47 \AA$ with tetra fluoro phenyl ring centre while Ala99 forms two hydrophobic $\pi$-alkyl interaction with ring centres of choromone structure are at the distance of 4.64, 4.86 A. Arg94, Ala213, Lys214 shows hydrophobic $\pi$-alkyl interaction with ring centres of choromone structure are at the distance of 5.44, 4.42, 5.39 and Gly 101 form a carbon hydrogen bond interaction with fluorine atom at the distance of $3.34 \AA$.

\subsubsection{For FHM}

The active amino acid Ser200, His207 forms conventional $\mathrm{H}$-bond interaction with fluorine atoms at the distance of 3.41, $3.38 \AA$ whereas Ser200, Thr241 shows conventional $\mathrm{H}$-bond with $\mathrm{NH}$ bond, oxygen atom in a ring at the distance of 2.32, 3.12 A. Asp121, Ser200 have halogen interaction with fluorine atoms at the distance of $3.51,3.29 \AA$ while Trp243 forms two hydrophobic $\pi-\pi$ T shaped interaction with ring centres of choromone structure are at the distance of 4.65, $4.68 \AA$ A. Ala204, Trp243 form hydrophobic $\pi$-sigma interaction having the distances $3.74,3.54 \AA$ with ring centres of tetra fluoro phenyl and phenyl ring respectively. Val298, Val301 shows hydrophobic $\pi$-alkyl interaction with phenyl ring centre are at the distance of $5.42,4.52 \AA$.

\subsubsection{For PFH}

The amino acid Tyr35, Gln237 forms conventional H-bond interaction with same fluorine atom at the distance of 3.29, $3.24 \AA$ Ahereas val44, Lys 45 shows conventional $\mathrm{H}$-bond with oxygen atom in a ring at the distance of 3.16, 3.01 A. Pro48 having two carbon hydrogen bond interaction with fluorine atom and $\mathrm{C}=\mathrm{O}$ group at the distance of 3.43 , $3.54 \AA$ while Glu50, Arg269 shows halogen interaction 
with fluorine atoms at the distance of 3.68, 3.60 A. Gly288 form a conventional $\mathrm{H}$-bond interaction with $\mathrm{C}=\mathrm{O}$ group and Arg269 has a carbon hydrogen bond interaction with fluorine atom at the distance of 3.20 and $3.26 \AA$. Gly288 forms hydrophobic $\pi$-sigma interaction with ring centre of tetra fluoro phenyl and hydrophobic amide $\pi$-stacked interaction with ring centre of choromone structure at the distance of 3.59 and $3.97 \AA$. Arg43, Val44 shows hydrophobic $\pi$-alkyl interaction withring centres of choromone structure are at the distance of $4.84,5.34 \AA$

\subsection{Interactions of TPC, FHM, PFH with 6DM8}

\subsubsection{For TPC}

The amino acids Asp200 shows two salt-bridge $\mathrm{H}$-bond with $\mathrm{NH}$ bond at the distances of 2.66, $2.17 \AA$ but Asn64 form conventional $\mathrm{H}$-bond and Asp200 form halogen interaction with fluorine atoms at the distance of 3.33, $3.22 \AA$ A. Tyr59 shows two hydrophobic interactions with ring centres of choromone structure at the distances of $3.74,4.31 \AA$ A whereas Tyr5 form hydrophobic $\pi-\pi$ stacked interaction with tetra fluoro phenyl ring at the distance of 4.41 Å. Trp125 has a hydrophobic $\pi-\pi$ T shaped interaction and Ala151 form hydrophobic $\pi$-alkyl interaction with choromone ring structure having the distances of 5.06, 5.41 respectively.

\subsubsection{For FHM}

The amino acid Asp200 show conventional $\mathrm{H}$-bond with $\mathrm{NH}$ bond and halogen interaction with fluorine atom at the distances of $2.48,3.26 \AA$. Tyr59 shows two hydrophobic $\pi-\pi$ stacked interactions with ring centres of choromone structure at the distances of $3.74,4.36 \AA$ whereas Tyr 5 form hydrophobic $\pi-\pi$ stacked interaction with tetra fluoro phenyl ring at the distance of $4.51 \AA$ A. Trp125 has a hydrophobic $\pi-\pi$ T shaped interaction and Ala151 form hydrophobic $\pi$-alkyl interaction with choromone ring structure having the distances of 5.06, $5.43 \AA$ A respectively.

\subsubsection{For PFH}

The amino acid Asp200 shows two conventional H-bond with $\mathrm{NH}$ bond and Asn64, Asp200 halogen interaction with fluorine atom at the distances of 2.63, 2.25 and 3.31, 3.37. . Tyr59 shows two hydrophobic $\pi-\pi$ stacked interactions with ring centres of choromone structure at the distances of 3.67, $4.09 \AA$ whereas Tyr5, Trp15 form hydrophobic $\pi-\pi$ stacked interaction with tetra fluoro phenyl ring, second ring centre at the distance of $4.43,5.93 \AA$. Trp152 has a hydrophobic $\pi-\pi$ T shaped interaction and Ala151 form hydrophobic $\pi$-alkyl interaction with phenyl ring centre having the distances of 5.56, 5.12 A respectively.

\subsection{Interactions of TPC, FHM, PFH with 2AYN}

\subsubsection{For TPC}

The active residues Arg123, Lys129, Arg441 forms conventional $\mathrm{H}$-bond interaction with $\mathrm{C}=\mathrm{N}$, fluorine atom and $\mathrm{C}=\mathrm{O}$ group at the distance of $2.94,3.24,3.00 \AA$ and $\mathrm{Cys} 104$ forms conventional and $\pi$-donor $\mathrm{H}$-bond with oxygen atom and centre of the ring of chromone structure at the distance of 3.30,4.01 A. Pro103 formulate two hydrophobic $\pi$-alkyl interaction with the ring centres of chromone structure at the distances are 5.38, 5.32 ̊. Val439, Arg441, Pro103 shows hydrophobic $\pi$-alkyl interaction with centre of tetra fluoro phenyl ring at the distance of $4.54,4.86$, $4.41 \AA$ while Lys 440 has a halogen interaction at the distance of $3.67 \AA$ with one of the fluorine atom attached with tetra fluoro phenyl ring.

\subsubsection{For FHM}

The active residues Asn413, Tyr416 forms conventional $\mathrm{H}$-bond interaction and Phe405, Cys414 shows halogen interaction with fluorine atomsat the distance of 3.30, 3.24 and 3.26, $3.03 \AA$ and Arg482 form a $\pi$-donor $\mathrm{H}$-bond with centre of tetra fluoro phenyl ring at the distance of $3.66 \AA$. Phe373 formulate two hydrophobic $\pi-\pi$ stacked interaction and Pro402 shows two with hydrophobic $\pi$-alkyl interaction the ring centres of chromone structure at the distances are 3.78, $4.01 \AA$ and 4.38, 5.27 ̊̊. Pro481, Ar482 forms hydrophobic $\pi$-alkyl interaction with centre of tetra fluoro phenyl ring at the distance of 5.48, $4.79 \AA$.

\subsubsection{For PFH}

The active residues Leu174 forms two conventional $\mathrm{H}$-bond interaction with fluorine atom and Thr165 has a conventional $\mathrm{H}$-bond interaction with $\mathrm{C}=\mathrm{O}$ group are at the distance of 3.02, 3.48 and $3.08 \AA$. Ala154, Asp157 shows two halogen interactions with fluorine atoms at the distance of 3.50, 3.02, 3.59, $3.48 \AA$ whereas Pro170 forms two hydrophobic $\pi$-alkyl interaction the ring centres of chromone structure at the distances are 4.83, 5.07. Ile173 displays a $\pi$-sigma interaction and Asp157 indicates amide $\pi$-stacked interaction with tetra fluoro phenyl ring centre at the distances of 3.33, 4.20 but Ala154 forms a carbon hydrogen bond interaction with fluorine atom at the distance $3.56 \AA$. Leu158, lle169 forms hydrophobic $\pi$-alkyl interaction with ring centres of tetra fluoro phenyl and chromone structure respectively at the distances of $4.56,4.36 \AA$. 


\subsection{Interactions of TPC, FHM, PFH with 5NAD}

\subsubsection{For TPC}

Amino acids Asp608, Ile531 form conventional $\mathrm{H}$-bond with $\mathrm{NH}$ bond at the distance of 2.57, 2.85 $\AA$ and Met671, Val539, Lys553, lle663 shows hydrophobic $\pi$-alkyl interaction with centres of the rings of chromone structure at the distances are 5.10, 5.11, 5.16, 5.33 $\AA$. Ile663, form hydrophobic $\pi$-sigma interaction and Met671 form $\pi$-sulfur interaction with centre of chromone structure at the distance of 3.84, 3.65 $\AA$. Asp608 formulate halogen interaction with one of the fluorine atom attached with tetra fluoro phenyl ring and Ile531 has a hydrophobic $\pi$-alkyl interaction with centre of tetra fluoro phenyl ring areat the distance of 3.13,4.60 Å respectively.

\subsubsection{For FHM}

Amino acid Asp608 form halogen interaction with fluorine atom and electrostatic $\pi$-anion interaction with tetra fluoro phenyl ring centre at the distance of 3.21, $4.95 \AA$ and lle663 shows hydrophobic $\pi$-sigma and $\pi$-alkyl interaction with centres of the rings of chromone structure at the distances are 3.73, $5.23 \AA \AA$. Met671 shows a $\pi$-sulfur and hydrophobic $\pi$-alkyl interaction whereas Val539 forms two hydrophobic $\pi$-alkyl interaction with centres of the rings of chromone structure at the distances of 3.73, 5.47 and 4.52, $5.43 \AA$. Ile531, Lys553 have hydrophobic $\pi$-alkyl interaction with tetra fluoro phenyl ring centre, phenyl ring centre at the distance of $4.69,5.33 \AA$ Å respectively.

\subsubsection{For PFH}

Amino acid Gln670 forms two halogen interaction both are at the distances 3.49 $\AA$ and Glu571, Asp664 shows a halogen interaction are at the distances of 3.27, $3.30 \AA$ with fluorine atoms. Lys553 electrostatic $\pi$-cation interaction with tetra fluoro phenyl ring centre and Cys604 shows a $\pi$-sulfur interaction with centre of phenyl ring at the distance of 4.61, 5.79 Å. Lys553, lle663, Met671 shows hydrophobic $\pi-a l k y l$ interaction with tetra fluoro phenyl ring centre and Ile 531 indicates two hydrophobic $\pi$-alkyl interaction with ring centres of chromone structure are at the distances of 4.91, 5.24, 4.76 and 5.14, $4.98 \AA$ A. Leu654, Pro673 forms hydrophobic $\pi$-alkyl interaction with ring centres of tetra fluoro phenyl and chromone structure respectively at the distances of 5.16, $5.37 \AA$.

\subsection{Interactions of 5-fluorouracil (FU) and azathioprine (AP) with 4AT9, 6DM8, 2AYN and 5NAD}

\subsubsection{AP and 4AT9}

Amino acids Gly106, Lys 110 forms conventional H-bond interaction with $\mathrm{NO}_{2}$ group at the distance of 3.12, 3.16 whereas Thr112, Asp246 shows carbon hydrogen bond interaction with $\mathrm{H}(2)$ atom of imidazole ring at the distance of $2.87,2.82 \AA$. His207 gives $\pi$-sulfur interaction with sulphur atom and hydrophobic $\pi-\pi \mathrm{T}$ shaped interaction with imidazole ring centre at the distances of 5.58, $5.42 \AA$. Pro242 forms two hydrophobic $\pi$-alkyl interaction at the distance of $5.30,4.76 \AA$ with centre of purine structure and Ala204 has a hydrophobic $\pi$-alkyl interaction with imidazole ring centre at the distance of $4.35 \AA$. Asp246 shows conventional $\mathrm{H}$-bond with $\mathrm{NH}$ bond of imidazole ring and Ser107 form a carbon hydrogen bond with nitrogen atom of pyrimidine ring are at the distance of $1.86 \AA$ and $3.38 \AA$.

\subsubsection{FU and 4AT9}

Amino acids Ser281, Ser289 forms conventional H-bond interaction with $\mathrm{OH}$ bond, fluorine atom at the distances of 3.00, $3.13 \AA$ whereas Gly282, lle283 indicates carbon hydrogen bond interaction with $\mathrm{H}(1)$, nitrogen atom attached with $\mathrm{H}(3)$ are at the distances of $2.76,3.39 \AA$. Phe 34 formulate a $\pi$-donor $\mathrm{H}$-bond having $3.15 \AA$ distance with $\mathrm{H}(4)$ atom.

\subsubsection{AP and 6DM8}

The active Amino acids Arg148 shows two conventional $\mathrm{H}$-bond interaction with nitrogen atoms of purine ring structure at the distance of 3.27, $3.19 \AA$ whereas Asp200 forms two carbon hydrogen bond with $\mathrm{H}(4)$ atom of imidazole ring, $\mathrm{H}(7)$ atom of $\mathrm{CH}_{3}$ group respectively are at the distance of 3.00, $2.80 \AA$. Glu170, Glu61 form carbon hydrogen bond with $\mathrm{H}(2)$ atom of imidazole ring are at the distance of 2.52, $3.06 \AA$ and Met 115 has a $\pi$-sulfur interaction with sulphur atom of the ligand with the distance of $5.99 \AA$. Trp152 forms different categories of hydrophobic interactions are four $\pi-\pi$ T shaped; two $\pi-\pi$ stacked and a $\pi$-alkyl with ring centres of purine structure are at the distances 5.62, 5.12, 5.47, 5.31; 5.09, 4.58 and $3.71 \AA$ respectively. Arg129, Glu61 forms electrostatic $\pi$-cation, $\pi$-anion interaction with imidazole ring centre at the distances 3.78, 3.84 A. 


\subsubsection{FU and 6DM8}

Amino acid Gln290 shows a conventional H-bond and carbon hydrogen bond interactions with $\mathrm{H}(3), \mathrm{H}(2)$ atoms at the distance of 2.76, $3.07 \AA$ while Thr240 form a carbon hydrogen bond interaction with $\mathrm{H}(4)$ atom attaching $\mathrm{CH}_{3}$ group at the distance of $3.09 \AA$. Gly295 forms a conventional $\mathrm{H}$-bond interaction with $\mathrm{H}(4)$ atom and two halogen interaction with fluorine atom are at the distance of 2.06, 2.84, 3.44 Å. Arg291, Glu298 formulates conventional $\mathrm{H}$-bond, halogen interaction respectively with same fluorine atom at the distance of $3.06,2.98 \AA$.

\subsubsection{AP and 2AYN}

The active residues Cys414, arg482 forms conventional $\mathrm{H}$-bond interaction with nitrogen atom and hydrogen atom of imidazole ringattached with pyrimidine ring and Tyr416 form carbon hydrogen bond interaction with $\mathrm{H}(2)$ atom at the distance of 2.29, $2.98 \AA$ and $2.35 \AA$. Arg482 formulate hydrophobic $\pi$-alkyl interaction with the attached ring centres at the distances are $4.34,5.49 \AA$. Phe373 has a hydrophobic $\pi-\pi$ stacked interaction and Pro402 shows a hydrophobic $\pi$-alkyl interaction with centre of imidazole ring at the distance of $3.84,4.80 \AA$.

\subsubsection{FU and 2AYN}

The active residue Phe405 forms two conventional $\mathrm{H}$-bond interaction with $\mathrm{H}(3), \mathrm{H}(4)$ atoms and halogen interaction with fluorine atom at the distance of 2.40, 2.05, $3.09 \AA$ whereas Cys 414 two conventional H-bond interaction with $\mathrm{H}(3)$, oxygen atom attached with $\mathrm{H}(2)$ at the distance of 3.09, $3.56 \AA$. Amino acid Asn413 formulates two conventional $\mathrm{H}$-bond interaction with oxygen atom attached with $\mathrm{H}(1)$, fluorine atom at the distance of $3.33,2.98 \AA$ and Ser404 has a $\mathrm{H}$-bond interaction with $\mathrm{H}(4)$ atomat the distance of $2.80 \AA$.

\subsubsection{AP and 5NAD}

Amino acid lle531form conventional $\mathrm{H}$-bond with $\mathrm{NH}$ bond of imidazole ring attached with pyridine ring at the distance of $2.36 \AA$ and Asp664 shows a carbon hydrogen bond at the distance of $2.68 \AA$ with $\mathrm{H}(4)$ atom of imidazole ring attached with pyridine ring. Ile531, lle663 forms hydrophobic $\pi$-sigma interaction with centre of imidazole ring attached with pyridine ring at the distance of 3.55, $3.82 \AA$ A Val539 formulate two hydrophobic $\pi$-alkyl interaction with centres of purine ring are at the distance of 5.20, $5.13 \AA$ A while Met671 has a hydrophobic $\pi$-alkyl interaction with centre of imidazole ring. Leu654, lle663 shows hydrophobic $\pi$-alkyl interaction with centres of pyrimidine ring at the distance of 5.17, $4.80 \AA$ respectively.

\subsubsection{Fu and 5NAD}

Amino acid Tyr725 forms conventional $\mathrm{H}$-bond with $\mathrm{H}(2)$, $\mathrm{H}(3)$, fluorine atoms are at the distances of 2.30, 2.14, $3.14 \AA$ respectively and Glu755 show a conventional $\mathrm{H}$-bond with $\mathrm{H}(3)$ atom at the distance of $2.99 \AA$.

TPC, FHM and PFH molecules formed hydrophobic and hydrogen bond interactions with the targets and with more negative binding energy showing high inhibiton efficiency. Also interaction energies are higher than that of 5-fluorouracil and azathioprine. Hence chromone derivatives have anticancer and antiproliferative properties similar to that of reference drugs.

\section{Conclusion}

The optimized structures of chromones have been carried out using DFT method and their frequencies and geometrical parameters were also determined. Maximum of $\varepsilon$ in the existing bonds in TPC, FHM and PFH, attributes to the bonds involving in aromatic region for $\mathrm{C} 23-\mathrm{C} 24$ and C23-C29 in TPC, C24-C25 and C24-C31 in FHM and C24-C25, and C7-C9 in PFH respectively that points toward the $\pi$-bond interactions between the corresponding atoms. First order hyperpolarizability of FHM, TPC and PFH are 140, 134 and 69 times that of urea. Molecular properties such as frontiers orbitals, gap energies and reactivity descriptors have also been discussed. The decrease in gap energy makes the flow of electrons easier so the molecules becomes soft and reactive. The calculated MEP maps show the positive potential sites are favourable for nucleophilic attack, whereas the negative potential sites are favourable for the electrophilic attack. Docking results were discussed based on the different interactions between the ligands and proteins. From the results of Autodock, TPC and PFH have maximum binding energy values of $-9.6 \mathrm{kcal} / \mathrm{mol}$ for $6 \mathrm{DM} 8$ while for $\mathrm{FHM}$ binding energy is $-8.6 \mathrm{kcal} / \mathrm{mol}$ for 5NAD. Antitumor and antiproliferative activities of hydrazine's were found to be higher than standared molecules.

Author contributions All authors conceived and designed the calculations. Analyzed and interpreted the data; contributed materials, analysis tools or data and software; wrote the paper.

\section{Compliance with ethical standards}

Conflict of interest The authors declare that they have no conflict of interest. 
Open Access This article is licensed under a Creative Commons Attribution 4.0 International License, which permits use, sharing, adaptation, distribution and reproduction in any medium or format, as long as you give appropriate credit to the original author(s) and the source, provide a link to the Creative Commons licence, and indicate if changes were made. The images or other third party material in this article are included in the article's Creative Commons licence, unless indicated otherwise in a credit line to the material. If material is not included in the article's Creative Commons licence and your intended use is not permitted by statutory regulation or exceeds the permitted use, you will need to obtain permission directly from the copyright holder. To view a copy of this licence, visit http://creativecommons. org/licenses/by/4.0/.

\section{References}

1. Wang M, Wang X, Li X, Yang Z, Guo Z, Zhang J, Ma J, Wei C (2020) A coumarin fusd 'off-on' fluorescent probe for highly selective detection of hydrazine. Spectrochim Acta 230:118075. https:// doi.org/10.1016/j.saa.2020.118075

2. Pan MH, Lai CS, Ho CT (2010) Anti-inflammatory activity of natural dietary flavonoids. Food Function 1:15-31. https://doi. org/10.1039/COFO00103A

3. Ilboudo DP, Basilico N, Parapini S, Corbett Y, D'Alessandro S, Dell'Agli M, Cogh P, Karou SD, Sawadogo R, Gnoula C, Simpore J, Nikiema JB, Monti D, Boisio E, Taramelli D (2013) Antiplasmodial and anti-inflammatory activities of Canthium henriquesianum (K.Schum), a plant used in traditional medicine in Burkina Faso. J Ethnopharmacol 148:763-769. https://doi.org/10.1016/j. jep.2013.04.049

4. Gomes A, Freitas M, Fernandes E, Lima JLFC (2010) Biological activities of 2-styrylchromones. Mini-Rev Medic Chem 10:1-7. https://doi.org/10.2174/138955710791112550

5. Shebel M, Adly OMI, Taha A, Elabd NN (2017) Structural variety in copper(II) complexes fo 3-formylchromone: synthesis, spectral, thermal, molecular modelling and biological studies. J Mol Struct 1147:438-451. https://doi.org/10.1016/j.molst ruc.2017.06.085

6. Vieira UC, Omuro K, Fatibello-Filho O (2002) Sweet potato (Ipomoea batatas (L) Lam.) tissue as a biocatalytst in a paraffin/ graphite biosensor for hydrazine determination in boiler water. Anal Lett 14:2221-2231. https://doi.org/10.1081/AL-120016097

7. Silva CFM, Batista VF, Pinto DCGA, Silva AMS (2018) Challenges with chromone as a privileged scaffold in drug discovery. Expert Opin Drug Discov 19:795-798. https://doi.org/10.1080/17460 441.2018.1494720

8. Duan YD, Jiang YY, Guo FX, Chen LX, Xu LI, Zhang W, Liu B (2019) The antitumor activity of naturally occurring chromones: a review. Fitoterapia 135:114-129. https://doi.org/10.1016/j.fitot e.2019.04.012

9. Emami S, Ghanbarimasir Z (2015) Recent advances of chroman4-one derivatives: synthetic approaches and bioactivities. Eur J Med Chem 93:539-563. https://doi.org/10.1016/j.ejmec h.2015.02.048

10. Barve V, Ahmed F, Adsule $S$, Banerjee $S$, Kulkarni S, Katiyar $P$, Anson CE, Powell AK, Padhye S, Sarkar FH (2006) Synthesis, molecular characterization and biological activity of novel synthetic derivatives of chromen-4-one in human cancer cells. J Med Chem 49:3800-3808. https://doi.org/10.1021/jm051068y

11. Marzano C, Pellei M, Tisato F, Santini C (2009) Copper complexes as anticancer agents. Anticancer Agents Med Chem 9:185-211. https://doi.org/10.2174/187152009787313837

12. Kunde SP, Kanade KG, Karale BK, Akolkar HN, Randhavane PV, Shinde ST (2019) Synthesis and characterization of nanostructured $\mathrm{Cu}-\mathrm{ZnO}$ : an efficient catalyst for the preparation of (E)-3-styrylchromones. Arab J Chem 12:5212-5222. https ://doi.org/10.1016/j.arabjc.2016.12.015

13. Olomola TO, Klein R, Kaye PT (2016) Application of Baylis-Hillman methodology in the direct construction of chromone derivatives. Tetrahedron 72(3):392-395. https://doi.org/10.1016/j. tet.2015.11.039

14. Reis J, Gaspar A, Milhazes N, Borges F (2017) Chromone as a privileged scaffold in drug discovery: recent advances. J Med Chem 60:7941-7957. https://doi.org/10.1021/acs.jmedchem.6b01720

15. Silva CFM, Pinto DCGA, Silva AMS (2016) Chromones: a promising ring system for new anti-inflammatory drugs. Chem Med Chem 11:2252-2260. https://doi.org/10.1002/cmdc.201600359

16. Arjunan V, Subramanian S, Mohan S (2004) FTIR and FTR spectral studies of 2-amino-6-bromo-3-formylchromone. Spectrochim Acta 60:995-1000. https://doi.org/10.1016/S1386 $-1425(03) 00330-5$

17. Elsayed SA, Butler IS, Claude BJ, Mostafa SI (2015) Synthesis, characterization and anticancer activity of 3-formylchromone benzoylhydrazone metal complexes. Transition Met Chem 40:179-187. https://doi.org/10.1007/s11243-014-9904-z

18. Mariappan G, Sundaraganesan N (2014) FT-IR, FT-Raman, NMR spectra, density functional computations of the vibrational assignments (for monomer and dimer) and molecular geometry of anti-cancer drug 7-amino-2-methylchromone. J Mol Struct 1063:192-202. https://doi.org/10.1016/j.molstruc.2014.01.064

19. Harborne JB, Williams CA (2000) Advances in flavonoid research since 1992. Phytochemistry 55:481-504. https://doi. org/10.1016/S0031-9422(00)00235-1

20. Khadem S, Marles RJ (2012) Chromone and flavanoid alkaloids: occurrence and Bioactivity. Molecules 17:191-206. https://doi. org/10.3390/molecules17010191

21. Gül DS, Ogutcu H, Hayvali Z (2020) Investigation of photophysical behaviours and antimicrobial activity of novel benzo15-crown-5-substituted coumarin and chromone derivatives. J Mol Struct 1204:127569. https://doi.org/10.1016/j.molst ruc.2019.127569

22. Kulaczkowska AD, Bartyzel A (2013) Structural and physicochemical properties of 3-(3-carboxyphenylaminomethylene)2-methoxychroman-4-one. J Mol Struct 1033:67-74. https://doi. org/10.1016/j.molstruc.2012.08.013

23. Kulaczkowska AD, Bartyzel A (2011) The new organic ligand: 3-(5-carboxy-2-chlorophenylaminomethylene)-2-methoxychroman-4-one: structural, spectral and thermal aspects. J Mol Struct 997:87-93. https://doi.org/10.1016/j.molstruc.2011.05.003

24. Kanagalakshmi K, Premanathan M, Priyanks R, Hemalatha B, Vanagamudi A (2010) Synthesis, anticancer and antioxidant activities of 7-methoxyisoflavanone and 2,3-diarylchromanones. Eur J Med Chem 45:2447-2452. https://doi.org/10.1016/j.ejmec h.2010.02.028

25. Rajan YC, Kanakam CC, Selvamb SP, Murugesan K (2007) A study on the synthesis and biological and optical properties of methylene-dinaphthyl bis-chromanones: the utility of BaylisHillman adducts. Tetrahedron Lett 48:8562-8565. https://doi. org/10.1016/j.tetlet.2007.09.097

26. Kornev MY, Tishin DS, Obydennov DL, Sosnovskikh VY (2020) Reactions of 3-functionalized chromones with triacetic acid lactone. Mendeleev Commun 30:233-235. https://doi. org/10.1016/j.mencom.2020.03.035

27. Kornev MY, Moshkin VS, Eltsov OS, Sosnovskikh VY (2016) Reactions of chromone-3-carboxylic acid and chromone-3-carboxamides with cyanoacetic acid hydrazide. Mendeleev Commun 26:72-74. https://doi.org/10.1016/j.mencom.2016.01.028

28. Keith T, Millam J (2009) Gaussview 5. Semichem. Inc., Shawnee Mission KS 
29. M.J.Frisch, G.W.Trucks, H.B.Schlegel, G.E.Scuseria, M.A.Robb, J.R.Cheeseman, G.Scalmani, V.Barone, B.Mennucci, G.A.Petersson, H.Nakatsuji, M.Caricato, X.Li, H.P.Hratchian, A.F.Izmaylov, J.Bloino, G.Zheng, J.L.Sonnenberg, M.Hada, M.Ehara, K.Toyota, R.Fukuda, J.Hasegawa, M.Ishida, T.Nakajima, Y.Honda, O.Kitao, H.Nakai,T.Vreven, J.A.Montgomery Jr, J.E.Peralta, F.Ogliaro, M.Bearpark, J.J.Heyd, E.Brothers, K.N.Kudin, V.N.Staroverov, T.Keith, R.Kobayashi, J.Normand, K.Raghavachari, A.Rendell, J.C.Burant, S.S.lyengar, R.Tomasi, M.Cossi, N.Rega, J.M.Millam, M.Klene, J.E.Knox, J.B.Cross, V.Bakken, C.Adamo, J.Jaramillo, R.Gomperts, R.E.Stratmann, O.Yazyev, A.J.Austin, R.Cammi, C.Pomelli, J.W.Ochterski, R.L.Martin, K.Morokuma, V.G.Zakrzewski, G.A.Voth, P.Salvador, J.J.Dannenberg, S.Dapprich, A.D.Daniels, O.Farkas, J.B.Foresman, J.V.Ortiz, J.Cioslowski, D.J.Fox, (2010) Gaussian 09, Revision B.01, Gaussian, Inc., Wallingford CT.

30. Cossi M, Barone V (1998) Analytical second derivatives of the free energy in solution by polarizable continuum models. J Chem Phys 109:6246. https://doi.org/10.1063/1.477265

31. Bohmann JA, Weinhold F, Farrar TC (1997) Natural chemical shielding analysis of nuclear magnetic resonance shielding tensors from gauge including atomic orbital calculations. J Chem Phys 107(4):1173-1184. https://doi. org/10.1063/1.474464

32. Guillaumont D, Nakamura S (2000) Calculation of the absorption wavelength of dyes using time dependent density functional theory (TD-DFT). Dyes Pigm 46(2):85-92. https://doi. org/10.1016/S0143-7208(00)00030-9

33. Kumar CSC, Panicker CY, Fun HK, Mary YS, Harikumar B, Chandraju S, Quah CK, Ooi CW (2014) FT-IR, molecular structure, first order hyperpolarizability, HOMO and LUMO analysis, MEP and NBO analysis of 2-(4-chlorophenyl)-2-oxoethyl 3-nitrobenzoate, spectrochim. Acta 126:208-219. https://doi.org/10.1016/j. saa.2014.01.145

34. da Silva CM, da Silva DL, Modolo LV, Alves RB, de Resende MA, Martins CV, de Fatima A (2011) Schiff bases: a short review of their antimicrobial activities. J Adv Res 2(1):1-8. https://doi. org/10.1016/j.jare.2010.05.004

35. Trott O, Olson AJ (2010) AutoDock Vina: improving the speed and accuracy of docking with a new scoring function, efficient optimization, and multithreading. J Comput Chem 31:455-461. https://doi.org/10.1002/jcc.21334

36. Mary YS, Panicker CY, Sapnakumari M, Narayana B, Sarojini BK, Al-Saadi AA, Van Alsenoy C, War JA (2015) FT-IR, NBO, HOMO-LUMO, MEP analysis and molecular docking study of 1-[3-(4-fluorophenyl)-5-phenyl-4,5-dihydro-1H-pyrazol1-yl] ethanone. Spectrochim Acta 136:483-493. https://doi. org/10.1016/j.saa.2014.09.061

37. Slomiak K, Lazarenkow A, Checinska L, Kusz J, Ochocki J, Modranka JN (2018) Synthesis, spectroscopic analysis and assessment of the biological activity of new hydrazine and hydrazide derivatives of 3-formylchromone. Molecules 23:2067. https://doi.org/10.3390/molecules 23082067

38. W RF (1990) BaderAtoms in molecules. A quantum theory. Oxford University Press, New York, NY

39. T.Keith, AIMAll Program, 2010, Version 10.12.11.

40. Roeges NPG (1994) A guide to the complete interpretation of infrared spectra of organic structures. John Wiley and Sons Inc., New York

41. Panicker CY, Varghese HT, Madhavan VS, Mathew S, Vinsova J, Van Alsenoy C, Mary YS, Mary YS (2009) FT-IR, FT-Raman, and computational calculations of 4-chloro-2-(3-chlorophenylcarbamoyl)phenyl acetate. J Raman Spectrosc 40:2176-2186. https ://doi.org/10.1002/jrs.2393

42. Anoop MR, Binil PS, Suma S, Sudarsanakumar MR, Mary YS, Varghese HT, Panicker CY (2010) Vibrational spectroscopic studies and computational study of ethyl methyl ketone thiosemicarbazone. J Mol Struct 969:48-54. https://doi.org/10.1016/j.molst ruc.2010.01.041

43. Kuruvilla TK, Prasana JC, Muthu S, George J, Mathew SA (2018) Quantum mechanical and spectroscopic (FT-IR, FT-Raman) study, NBO analysis, HOMO-LUMO, first order hyerpolarizability and molecular docking study of methyl[(3R)-3-(2methylphenoxy)-3-phenylpropyl]amine by density functional method. Spectrochim Acta 188:382-393. https://doi. org/10.1016/j.saa.2017.07.029

44. Beegum S, Mary YS, Mary YS, Thomas R, Armakovic S, Armakovic SJ, Zitko J, Dolezal M, Van Alsenoy C (2020) Exploring the detailed spectroscopic characteristics, chemical and biological activity of two cyanopyrazine-2-carboxamide derivatives using experimental and theoretical tools. Spectrochim Acta 224:117414. https://doi.org/10.1016/j.saa.2019.117414

45. El-Azab AS, Mary YS, Panicker CY, Abdel-Aziz AAM, Al-Suwaidan IA, Van Alsenoy C (2016) FT-IR, FT-Raman and molecular docking study of ethyl 4-(2-(4-oxo-3-phenethyl-3,4-dihydroquinazolin2-ylyhio)acetamido)benzoate. J Mol Struct 1111:9-18. https:// doi.org/10.1016/j.molstruc.2016.01.041

46. Mary YS, Aswathy VV, Panicker CY, Bielenica A, Brzoka P, Savczenko O, Armakovic S, Armakovic SJ, Van Alsenoy C (2016) Spectroscopic, single crystal XRD structure, DFT and molecular dynamics investigation of 1-(3-chloro-4-fluorophenyl)-3-[3(trifluoromethyl)phenyl]thiourea. RSC Adv 6:111997-112015. https://doi.org/10.1039/C6RA21396K

47. Mary YS, Varghese HT, Panicker CY, Ertan T, Yildiz I, Temiz-Arpaci O (2008) Vibrational spectroscopic studies and ab initio calculations of 5-nitro-2-(p-fluorophenyl)benzoxazole. Spectrochim Acta 71:566-571. https://doi.org/10.1016/j.saa.2007.12.041

48. Mary YS, Panicker CY, Sapnakumari M, Narayna B, Sarojini BK, Al-Saadi AA, Van Alsenoy C, War JA (2015) Molecular structure, FT-IR, vibrational assignments, HOMO-LUMO, MEP, NBO analysis and molecular docking study of ethyl-6-(4-chlorophenyl)-4-(4fluorophenyl)-2-oxocyclohex-3-ene-1-carboxylate. Spectrochim Acta 138:73-84. https://doi.org/10.1016/j.saa.2014.11.012

49. Raja M, Muhamed RR, Muthu S, Suresh M (2017) Synthesis, spectroscopic (FT-IR, FT-Raman, NMR, UV-Visible), first order hyperpolarizability, NBO and molecular docking study of (E)-1-(4bromobenzylidene)semicarbazide. J Mol Struct 1128:481-492. https://doi.org/10.1106/j.molstruc.2016.09.017

50. J. R. Browser, Inorganic Chemistry, Brooks, (1993) 721-725

51. Sinha D, Tiwari AK, Singh $S$, Shukla G, Mishra $P$, Chandra $H$ Mishra AK (2008) Synthesis, characterization, and biological activity of Schiff base analogues of indole-3-carboxaldehyde. Eur J Med Chem 43:160-165. https://doi.org/10.1016/j.ejmec h.2007.03.022

52. Karan YS, Yalduz S (2019) substituent effect study on the experimental 13C NMR chemical shifts of 3-(substituted phenyl)3a,4,8,-81-tetrahydro-1,3-dioxepino[5,6-d][1,2]isoxazoles. J Mol Struct 1193:158-165. https://doi.org/10.1016/j.molst ruc.2019.04.121

53. Milenkovic D, Avdovic E, Dimic D, Sudha S, Ramarajan D, Milanovic Z, Trifunovic S, Markovic ZS (2020) Vibrational and Hirshfeld surface analyses, quantum chemical calculations, and molecular docking studies of coumarin derivative 3-(1-m-toluidinoethylidene)-chromane-2,4-dione and its corresponding palladium(II) complex. J Mol Struct 1209:127935. https://doi.org/10.1016/j.molstruc.2020.127935

54. Dimic D, Milanovic Z, Jovanovic G, Sretenovic D, Milenkovic D, Markovic Z, Markovic JD (2020) Comparative structural, molecular docking/dynamics analysis and antiradical activity of octopamine and norepinephrine. Computat Biol Chem. https://doi. org/10.1016/j.compbiolchem.2019.107170 
55. Kumar VS, Mary YS, Pradhan K, Brahman D, Mary YS, Serdaroglu G, Rad AS, Roxy MS (2020) Conformational analysis and quantum descriptors of two new imidazole derivatives by experimental, DFT, AIM, molecular docking studies and adsorption activity on graphene. Heliyon. https://doi.org/10.1016/j.heliyon.2020. e05182

56. E.D.Glendening, A.E.Reed, J.E.Carpenter, F.Weinhold, (2003) NBO Version 3.1, Gaussian Inc., Pittsburgh, PA.

57. Mary YS, Varghese HT, Panicker CY, Girisha M, Sagar BK, Yathirajan HS, Al-Saadi AA, Van Alsenoy C (2015) Vibrational spectra, HOMO, LUMO, NBO, MEP analysis and molecular docking study of 2,2-diphenyl-4-(piperiidn-1yl)butanamide. Spectrochim Acta 150:543-556. https://doi.org/10.1016/j.saa.2015.05.090

58. Thomas R, Hossain M, Mary YS, Resmi KS, Armakovic S, Armakovic SJ, Nanda AK, Ranjan VK, Vijayakumar G, Van Alsenoy C (2018) Spectroscopic analysis and molecular docking of imidazole derivatives and investigation of its reactive properties by DFT and molecular dynamics simulations. J Mol Struct 1158:156-175. https://doi.org/10.1016/j.molstruc.2018.01.021

59. Shafieyoon P, Mehdipour E, Mary YS (2019) Synthesis, characterization and biological investigation of glycine-based sulfonamide derivative and its complex: Vibration assignment, HOMO-LUMO analysis, MEP and molecular docking. J Mol Struct 1181:244-252. https://doi.org/10.1016/j.molstruc.2018.12.067

60. Fleming I (2010) Molecular orbital and organic chemical reaction, reference. Hoboken, John Wiley and Sons

61. Parthasarathi R, Padmanabhan J, Elango $M$, Subramanian V, Chattaraj PK (2004) Intermolecular reactivity through the generalized philicity concept. Chem Phys Let 394:225-230. https:// doi.org/10.1016/j.cplett.2004.07.002

62. Chattaraj PK, Sarkar U, Roy DR (2006) Electrophilicity index. Chem Rev 106:2065-2091. https://doi.org/10.1021/cr040109f

63. Chattaraj PK, Giri S (2009) Electrophilicity index within a conceptual DFT framework. Annu Rep Prog Chem Sect C: Phys Chem 105:13-39. https://doi.org/10.1039/B802832J

64. Domingo LR, Rios-Gutierrez M, Perez P (2016) Applications of the conceptual density functional theory indices to organic chemistry reactivity. Molecules 21:748. https://doi.org/10.3390/ molecules 21060748

65. Mary YS, Varghese HT, Panicker CY, Thiemann T, Al-Saadi AA, Popoola SA, Van Alsenoy C, Jasem YA (2015) Molecular conformational analysis, vibrational spectra, NBO, NLO, HOMO-LUMO and molecular docking studies of ethyl 3-(E)-(anthracen-9-yl)prop-2-enoate based on density functional theory calculations. Spectrochim Acta 150:533-542. https://doi.org/10.1016/j. saa.2015.05.092

66. Kaya S, Erkan S, Karakas D (2021) Computational investigation of molecular structures, spectroscopic properties and antitumorantibacterial activities of some Schiff bases. Spectrochim Acta 244:118829. https://doi.org/10.1016/j.saa.2020.118829

67. Mary YS, Panicker CY, Sapnakumari M, Narayana B, Sarojini BK, Al-Saadi AA, Van Alsenoy C, War JA, Fun HK (2015) Molecular structure, FT-IR, vibrational assignments, HOMO-LUMO analysis and molecular docking study of 1-[5-(4-bromopheny)-3-(4fluorohenyl)-4,5-dihydro-1H-pyrazol-1yl]ethanone. Spectrochim Acta 136:473-482. https://doi.org/10.1016/j.saa.2014.09.060
68. Mary YS, Mary YS, Thomas R, Narayana B, Samshuddin S, Sarojini BK, Armakovic S, Armakovic SJ, Pillai GG (2019) Theoretical studies on the structure and various physico-chemical and biological properties of a terphenyl derivative with immense anti-protozoan activity. Polycyclic Aromat Compd. https://doi. org/10.1080/10406638.2019.1624974

69. Hossain M, Thomas R, Mary YS, Resmi KS, Aramkovic S, Armakovic SJ, Nanda AK, Vijayakumar G, Van Alsenoy C (2018) Understanding reactivity of two newly synthetized imidazole derivatives by spectroscopic characterization and computational study. J Mol Struct 1158:176-196. https://doi.org/10.1016/j. molstruc.2018.01.029

70. Aswathy VV, Mary YS, Jojo PJ, Panicker CY, Bielenica A, Armakovic S, Armakovic SJ, Brzozka P, Krukowski S, Van Alsenoy C (2017) Investigation of spectroscopic, reactive, transport and docking properties of 1-(3,4-dichlorophenyl)-3-[3-(trifluoromethyl) phenyl]thiourea (ANF:6): combined experimental and computational study. J Mol Struct 1134:668-680. https://doi. org/10.1016/j.molstruc.2017.01.016

71. Lagunin A, Stepanchikova A, Filimonov D, Poroikov V (2000) PASS: Prediction of activity spectra for biologically active substances. Bioinformatics 16:747-748. https://doi.org/10.1093/ bioinformatics/16.8.747

72. Zhang Y, Yang C, Zhang M, Liu H, Gong C, Zhang J, Xu S, Zou J, Kai Y, Li Y (2017) Interleukin enhancer-binding factor 3 and HOXC8 co-activate cadherin 11 transcription to promote breast cancer cells proliferation and migration. Oncotarget 8(64):107477-107491. https://doi.org/10.18632/oncotarget .22491

73. Xiang W, Yang CY, Bai L (2018) MCL-1 inhibition in cancer treatment. Onco Targets Ther 11:7301-7314. https://doi.org/10.2147/ OTT.S146228

74. Chen YJ, Ma YS, Fang Y, Wang Y, Fu D, Shen XZ (2013) Power and promise of Ubiquitin Carboxyl-Terminal Hydrolase 37 as a target of cancer therapy. Asian Pac J Cancer Prev 14(4):2173-2179

75. Tadesse S, Caldon EC, Tilley W, Wang S (2019) Cyclin-Dependent kinase 2 inhibitors in cancer therapy: an update. J Med Chem 62(9):4233-4251. https://doi.org/10.1021/acs.jmedchem.8b014 69

76. D.Duhovny, R.Nussinov, H.J.Wolfson, Efficient unbound docking of rigid molecules, in: Gusfield et al. (Eds.), Proceedings of the second workshop on algorithms in bioinformatics (WABI) Rome, Italy, lecture notes in computer science, vol. 2452 (2000) 185-200, Springer Verlag.

77. Schneidman-Duhovny D, Inbar Y, Nussinov R, Wolfson HJ (2005) Patchdock and Symmdock: servers for rigid and symmetric docking. Nucleic Acids Res 33:W363-W367. https://doi. org/10.1093/nar/gki481

78. Mary YS, Mary YS, Resmi KS, Kumar VS, Thomas R, Sureshkumar B (2019) Detailed quantum mechanical, molecular docking QSAR prediction, photovoltaic light harvesting efficiency analysis of benzil and its halogenated analogues. Heliyon 5:e2825. https:// doi.org/10.1016/j.heliyon.2019.e02825

Publisher's Note Springer Nature remains neutral with regard to jurisdictional claims in published maps and institutional affiliations. 